Review

\title{
Sustainable Cross-Laminated Timber Structures in a Seismic Area: Overview and Future Trends
}

\author{
Antonio Sandoli *, Claudio D'Ambra, Carla Ceraldi, Bruno Calderoni and Andrea Prota \\ Department of Structures for Engineering and Architecture, University of Naples Federico II, via Claudio 21, \\ 80125 Naples, Italy; claudio.dambra@uninat.it (C.D.); ceraldi@uninat.it (C.C.); calderon@uninat.it (B.C.); \\ aprota@uninat.it (A.P.) \\ * Correspondence: Antonio.sandoli@unina.it
}

Citation: Sandoli, A.; D'Ambra, C.; Ceraldi, C.; Calderoni, B.; Prota, A.

Sustainable Cross-Laminated Timber Structures in a Seismic Area: Overview and Future Trends. Appl. Sci. 2021, 11, 2078. https://doi.org/ 10.3390/app11052078

Academic Editors: Elmira Jamei and Panagiotis G. Asteris

Received: 26 January 2021

Accepted: 23 February 2021

Published: 26 February 2021

Publisher's Note: MDPI stays neutral with regard to jurisdictional claims in published maps and institutional affiliations.

Copyright: (c) 2021 by the authors. Licensee MDPI, Basel, Switzerland. This article is an open access article distributed under the terms and conditions of the Creative Commons Attribution (CC BY) license (https:/ / creativecommons.org/licenses/by/ $4.0 /)$.

\begin{abstract}
Cross-laminated timber (CLT) buildings are recognized as a robust alternative to heavyweight constructions, because beneficial for seismic resistance and environmental sustainability, more than other construction materials. The lightness of material and the satisfactory dissipative response of the mechanical connections provide an excellent seismic response to multi-story CLT buildings, in spite of permanent damage to timber panels in the connection zones. Basically, CLT constructions are highly sustainable structures from extraction of raw material, to manufacturing process, up to usage, disposal and recycling. With respect to other constructions, the potential of CLT buildings is that their environmental sustainability in the phases of disposal and/or recycling can be further enhanced if the seismic damage in structural timber components is reduced or nullified. This paper reports a state-of-the art overview on seismic performance and sustainability aspects of CLT buildings in seismic prone regions. Technological issues and modelling approaches for traditional CLT buildings currently proposed in literature are discussed, focusing the attention on some research advancements and future trends devoted to enhance seismic performance and environmental sustainability of CLT buildings in seismic prone regions.
\end{abstract}

Keywords: CLT buildings; sustainability; environment; seismic behavior; traditional connections; low-damage connections

\section{Introduction}

Timber-based structures are gaining popularity in residential and non-residential constructions marked in the last two decades, also in those countries not prone to the use of wood. This development is mainly due to the introduction of the high efficiency engineered and sustainable timber products such as Glue-Lam, cross-laminated timber (CLT) and Laminated Veneer Lumber (LVL) used for one and two-dimensional elements.

Cross-lam panel, originated in Austria in the early of 1990s, represents one of the most diffused mass timber products in Europe for low and mid-rise timber buildings. It has been estimated that the global annual production of CLT is growing exponentially in Europe, it was $25,000 \mathrm{~m}^{3}$ in $1996,340,000 \mathrm{~m}^{3}$ in $2010,650,000 \mathrm{~m}^{3}$ in 2015 , up to 1.2 million of $\mathrm{m}^{3}$ in 2020 [1,2] (Figure 1). Nevertheless, an annual increase of the manufactured CLT has been also recorded in the United States, Canada, Australia, Japan and New Zealand [3-5].

Together with its excellent seismic resistance, environmentally-friendly and ecosustainability properties have made wood a particularly appreciated building material. By contrast with other mass timber structures, boards used for CLT panels can be obtained from small-diameter trees: such trees have low commercial value and can be beneficial in maintaining a healthier forests habitat, because less vulnerable to wildfires [6].

Furthermore, aspects related to life-cycle assessment encouraged the use of CLT in building market: CLT, as well as other timber-based products, has better energy saving and carbon reduction performance than other traditional building materials. Boriesson et al. [7] demonstrated that compared with reinforced concrete-framed buildings, wooden-framed 
constructions consume approximately $80 \%$ more energy during the material production stages and release about 100-200\% more. With regards to CLT, Guo et al. [8] pointed out that, on a national level, a seven-story CLT building may result in a $29.4 \%$ energy saving (which is equivalent to $24.6 \%$ carbon reduction) when compared with reinforced concrete building in the operational stage. Liu et al. [9] compared the consumption between two seven-story buildings constructed using reinforced concrete and CLT panels: they demonstrated as the energy consumption for heating and cooling was $338 \mathrm{MJ} / \mathrm{m}^{2}$ and $231 \mathrm{MJ} / \mathrm{m}^{2}$ per annum for reinforced concrete and CLT, respectively.

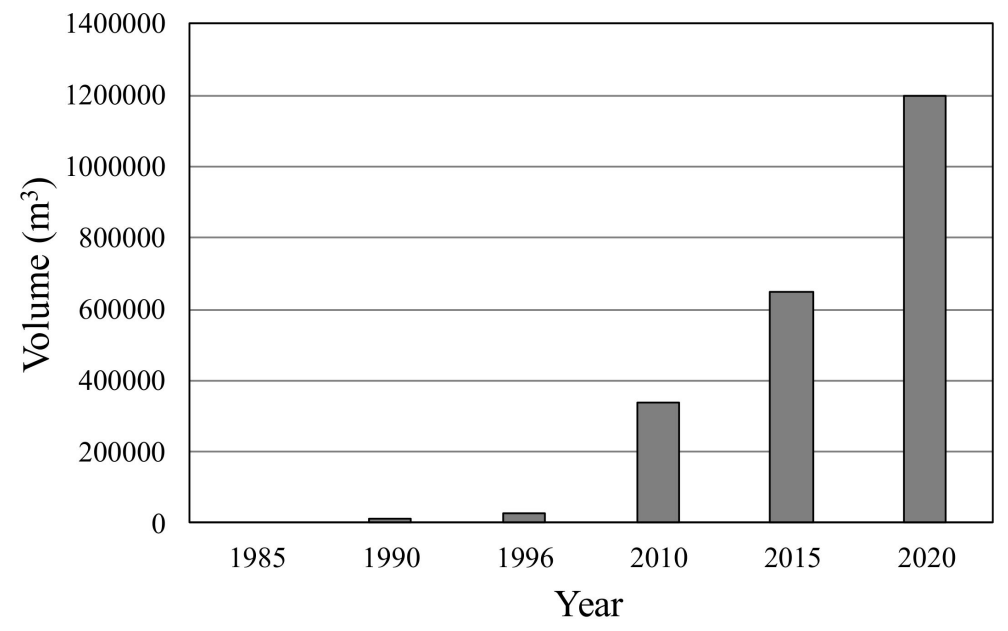

Figure 1. Volume in $\mathrm{m}^{3}$ of cross-laminated timber (CLT) manufacture in Europe.

The great potential for $\mathrm{CO}_{2}$ reduction achievable by wood structure buildings has been also proved. The $\mathrm{CO}_{2}$ emissions of houses with a concrete structure are $850 \mathrm{~kg} / \mathrm{m}^{2}$, compared with $250 \mathrm{~kg} / \mathrm{m}^{2}$ for wooden structures and $450 \mathrm{~kg} / \mathrm{m}^{2}$ for light-weight steel structures [10].

As far as the seismic resistance goes, the high strength-to-weight ratio allow medium and high-rise CLT buildings capable of withstanding high-intensity earthquakes [2,11], despite the lack of code prescriptions to design seismic-resistant CLT structures at national or international levels. The majority of prescriptions for the in-plane and out-of-plane checks of the panels at ultimate and serviceability limit states, as well as seismic design rules for multi-story buildings, can be found in literature papers or in manuals only. Nevertheless, the need to provide practical rules for design practice kicked off the update of some standards in Europe (Eurocode 5 [12] and Eurocode 8 [13]), even if these are not yet concluded [14,15].

Experimental, theoretical and numerical studies highlighted a satisfactory seismic performance of CLT buildings. A shake table test performed on full-scale multi-story buildings proved the capability of surviving high-intensity earthquakes, up to $0.82 \mathrm{~g}$ of peak-ground acceleration for a seven-story building [16,17] and up to $1.52 \mathrm{~g}$ for a two-story building [18], depending on lightness of material and behavior of mechanical connections.

Local tests on connections showed a significant energy dissipation capacity, if (correctly) designed to prevent brittle failure modes [19-23]. Mechanical connections, placed in the panel to panel and panel to foundation contact zones, named as hold-down (HD) and angle brackets $(\mathrm{AB})$, consist of thin steel plates nailed or screwed to timber panels and bolted to foundation: the first resist to tension forces and are used against uplift, while the second resist to shear forces and are used to withstand sliding. HD and AB play a crucial role on the seismic performance of CLT buildings because they are the main source of seismic energy dissipation.

In the perspective of performance-based seismic design (PBD), HDs and ABs may be regarded as "traditional" systems although introduced by a few years. Their failure mechanisms involve high damage to timber structural components after an earthquake, 
enough to be replaced by alternative systems. High damaging is in conflict with PDB philosophy, which requires high seismic performance and low damaging contemporarily satisfied by the structures.

Serious damage to timber parts affects also the sustainability related to the final part of life cycle of the construction, and in particular phases of the disposal and/or recycling of material. Basically, thanks to eco-sustainability of material and attention of manufacturers to produce environmentally certified products, CLT buildings are highly-sustainable constructions. However, the sustainability can be furtherly improved if design approaches oriented to seismic damage reduction on timber components are developed.

To this purpose, the first studies aimed at developing an "integrated design" between seismic-resistant and more sustainable timber constructions are under development; the main scope is that of introducing low-damage connections capable of (i) concentrating the seismic dissipation in replaceable connection systems and of (ii) reducing seismic damages on timber components [24-26].

This paper presents a state-of-the-art on the seismic behavior of traditional CLT buildings, focusing on the main research advancements aimed at enhancing both seismic performance and environmental sustainability. The first sections of the article are dedicated to the description of the technological aspects and seismic behavior of CLT buildings. In the following sections the different modelling strategies for multi-story buildings available in the scientific literature are illustrated and compared critically. The state-of-the-art allowed pros and cons of CLT constructions with regards to sustainability to be highlighted and to discuss critically (in the finale of the paper) about the new and future research trends concerning the seismic performance and environmental sustainability enhancing of CLT buildings.

\section{Cross-Laminated Timber (CLT) Panels}

CLT panel is a two-dimensional mass timber element composed of an appropriate number of layer of boards. The layers are made with adjacent boards or lamellae (usually not glued on the edges), rotated around at a right angle one each other and glued among them (Figure 2).

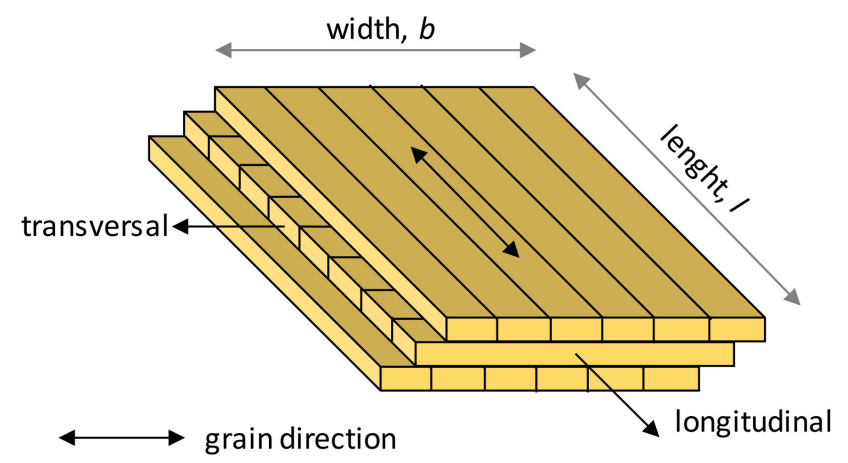

Figure 2. CLT panel lay-out.

Panel dimensions are variable as regards thickness ( $t)$, width (b) and length (l). The length can in theory be unlimited because the individual boards are finger-joined to create long boards. The number of layers is odd and vary from a minimum of three to a maximum of nine. In Table 1 are indicated the common dimensions used in building practice.

Table 1. Range of the geometrical characteristics of cross-laminated timber (CLT) panels.

\begin{tabular}{cc}
\hline Parameter & Commonplace \\
\hline Thickness $(\mathrm{t})$ & $60-300 \mathrm{~mm}$ \\
Width (b) & $1.20-4.80$ \\
Length (l) & up to $30 \mathrm{~m}$ \\
No. of layers & $3-5-7-9$ \\
\hline
\end{tabular}


The raw material consists of timber boards that have been strength graded according to standards (e.g., EN-14081-1 in Europe [27]). The cross-section of CLT usually comprises boards of the same strength in the two main direction, here indicated as "longitudinal" (axis of major strength and stiffness) and "transversal" (axis of minor strength and stiffness) in Figure 2. To make the most of the panel strength, wood with higher strength can be used in the main direction of the load.

As for the majority of engineered wood products, also for CLT panels soft-wood species are mainly used, such as spruce or less frequently larch or douglasia (that ensure greater durability to the panel). Depending on geographic area, the boards arrangement can be different [11], as represented in Figure 3.

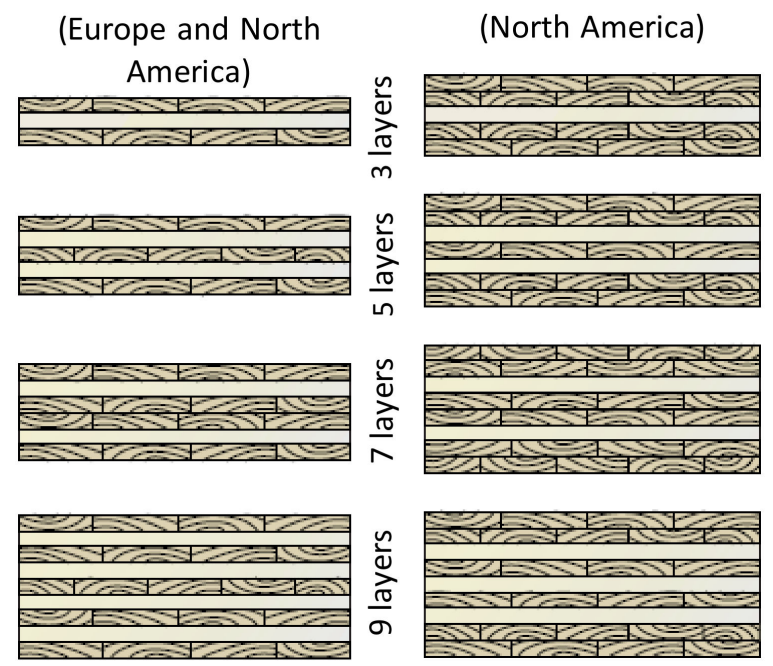

Figure 3. Number of layers and boards arrangement in CLT panels (image from [11]).

The cross-layered morphology provides high structural properties to CLT members, that can compete with other more traditional structural materials adopted for medium and high-rise buildings. The main advantages of CLT panels regard the structural features, thermal and sustainable aspects, as summarized in the following:

- In relation to their own-weight, CLT panels have a higher load-bearing capacity than most other construction materials: this means that high-rise buildings can be constructed with reduced masses.

- The cross-layered nature provides in-plane and out-of-plane load-carrying capacity and can be used either for vertical shear-walls (membranes) or floors (plates), as well as for other structural applications (bridges, sport arenas, curved elements, etc.).

- High in-plane strength and stiffness, even if differentiated between the longitudinal and transversal directions of the panel.

- Good dimensional stability against moisture variations: crossed layers reduce the shrinkage and swelling phenomena with respect to other timber-based products.

- Excellent energy efficiency and capacity of storing moisture and thermal energy.

- Ecofriendly, recyclable and renewable construction material with long service life (when correctly protected against moisture).

- Workability, slenderness and different sizes do not limit architectural design.

Despite the significant use in construction practice, CLT panels are not yet codified in national or international standards. In Europe, the European Technical Assessments (ETAs) represents the main reference document that codifies the CLT products indicating their specific properties for structural applications [28]. In compliance with ETAs, CLT panels are made with boards having a strength class corresponding to C16, C24 and C30.

Instead, the National Annexes to the European standards [29,30] specify the design rules and checks, although they have not been yet included in the Eurocode 5 [12]. In Eu- 
rope, the revised Italian Technical Document CNR DT 2016/2018-R1 [31] contemplates the use of the CLT and indicates its main characteristics for structural purposes.

In the United States, specific properties of CLT products and their structural uses for buildings are included in the International Building Code [32] while for strength and fire resistance checks it refers to the National Design Specification (NDS) for Wood Construction [33].

In Japan, the Building Standard Law has included the possibility of CLT constructions since 2016, but without providing design and checks rules. Instead, the reference guidelines for CLT constructions are contained in a specific manual released by the Japan CLT Association [34]. Also Australia and New Zealand lack specific design codes, but can rely only on guideline prescriptions [35].

In the meantime, engineers and researchers can trust on not-codified rules included in books or in manuals released by research groups or manufacturers, which offer recommendations based on experimental and numerical results. Useful documents are the manuals released by FP-Innovation in Canada [11], the Swedish one [2] or that issued by proHolz-Austria in 2015 [36], all contain indications for the structural design and strength checks at ultimate and service limit states for CLT panels.

\section{Traditional CLT Buildings}

\subsection{Technology}

Low and mid-rise traditional CLT buildings are made with CLT panels used for both vertical shear-walls and horizontal floors. The panels are prefabricated off-site and connected on the building site using metal connectors such as hold-downs, angle brackets, screws and nails.

Depending on their arrangement, the shear-walls can be divided in two groups: (i) single (or monolithic) and (ii) segmented (or coupled) walls. In the case (i) the wall has high width-to-height ratio, with width equal to plant dimension of the building and length corresponding to its inter-story height. In the case (ii) the wall is composed by narrow panels joined to each other by means of vertical step joints [21,37], and width-to-height ratios greater than 0.20 are advisable [31].

CLT traditional buildings are constructed using the "platform" technique, i.e., the vertical continuity of the walls is interrupted at each story by horizontal panels (floors) included, as a "sandwich", between two consecutive vertical panels (Figure 4). At the ground floors the vertical panels are directly placed on a reinforced concrete foundation or a horizontal timber beam interposed between foundation and vertical panels. Low-rise buildings can be also built-up adopting the "balloon" technique (Figure 5), where the vertical continuity of the walls is not interrupted by the floors at each story, but they are connected on the internal side of the vertical walls by means of specific connection devices [38].

Panel to panel and panel to foundation connections consist of mechanical steel to timber connections, made with punched cold-formed thin steel plates-typically hold-downs (HD) and angle brackets (AB) - fastened to the timber panels with ring shanks nails or screws and bolted to the foundations (Figure 4).

Being characterized by a high level of prefabrication, several connection-types are needed to connect the panels among them (in addition to HDs and ABs), such as metal fasteners between the orthogonal walls, metal fasteners to join the floor panels or to connect segmented walls against sliding (Figure 4). Connections between floor panels and between segmented walls can be realized with different types of fasteners arranged differently, typically overlapped joints with inclined screws running at $45^{\circ}$, half-lap joints with vertical screws or other solutions which can be found in $[2,11]$.

Door and window openings are obtained as a function of the type of the vertical walls arrangement: by cutting the zone interested by the opening in the case of monolithic walls, or by assembling multiple elements in the case of segmented walls. In the first case the 
lintels, i.e., horizontal CLT panels above the openings, have the same cross layout of the vertical panels, while in the second case the layout can be also different.
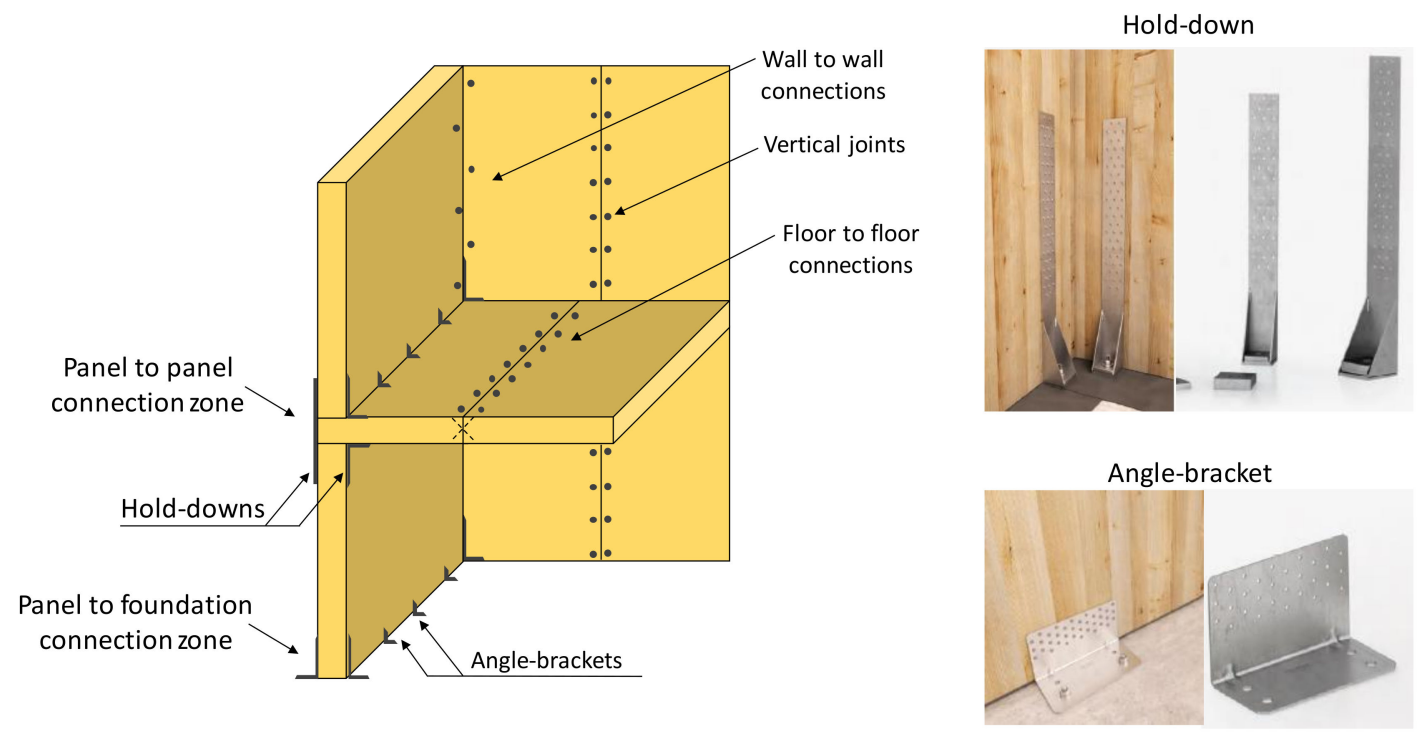

Figure 4. Typical connections for CLT buildings constructed with platform technique.

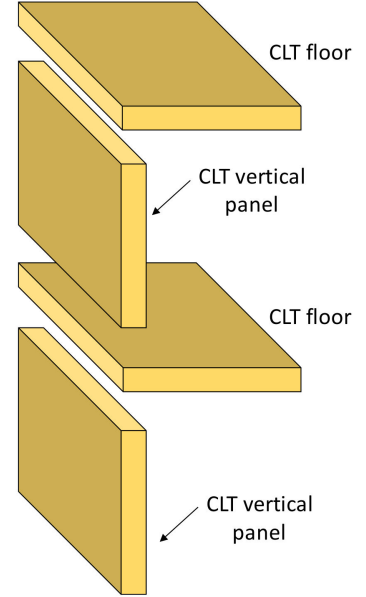

(a)

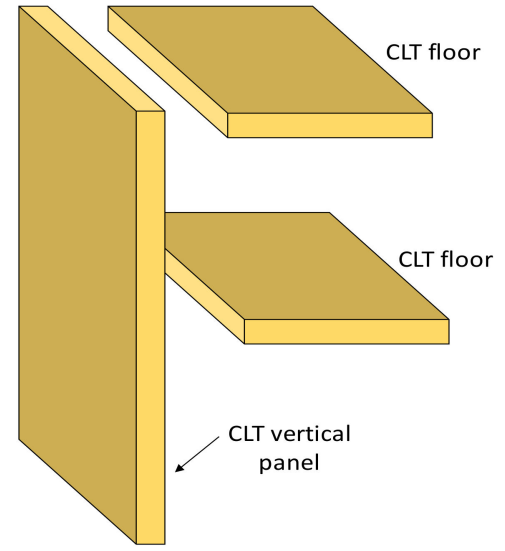

(b)

Figure 5. Constructional techniques for CLT buildings: (a) platform, (b) balloon.

\subsection{Seismic Behavior}

Despite the high number of connections, CLT buildings exhibit a favorable box-like behavior under combined seismic actions and gravity loads.

With regards the gravity loads patterns only, particular precautions on connection systems are not necessary. Due to the platform constructive technique, the compressive forces at the interface between the vertical panels and the interposed floor panels (in the sequel referred as "panel to panel" contact) are transferred by contact. Such compressive forces load in orthogonal to grain direction the floor panels in which a low-strength of material is expected, because the orthogonal to grain compressive strength $\left(f_{c, 90}\right)$ is about $1 / 10$ of the parallel to grain compression strength $\left(f_{\mathrm{c}, 0}\right)$. This issue sets limits also with respect to the maximum height of the buildings, which should be at most 10 storey in height in order to avoid high stress levels on the floor panels. On the contrary, the panels cross-section dimensions typically used for low and mid-rise buildings are overestimated with respect to the amount of the gravity loads. It is worth underlining that, in case of 
balloon constructive technique the issue of orthogonal to grain loading of panel floors does not arise because they do not interrupt the vertical continuity of the wall.

Seismic actions, instead, entail a more complex load path which involves the mechanical connections in the panel to panel and the panel to foundation contact zones, as schematically represented in Figure 6. Hold-downs are devoted to face uplift and then withstand principally the tension forces due to the overturning moment, while angle-brackets contrast principally the sliding and then absorb the shear forces. While the timber-totimber contact ensures the transferring of compression forces due to horizontal actions at the panel-to-panel or panel-to-foundation interfaces.

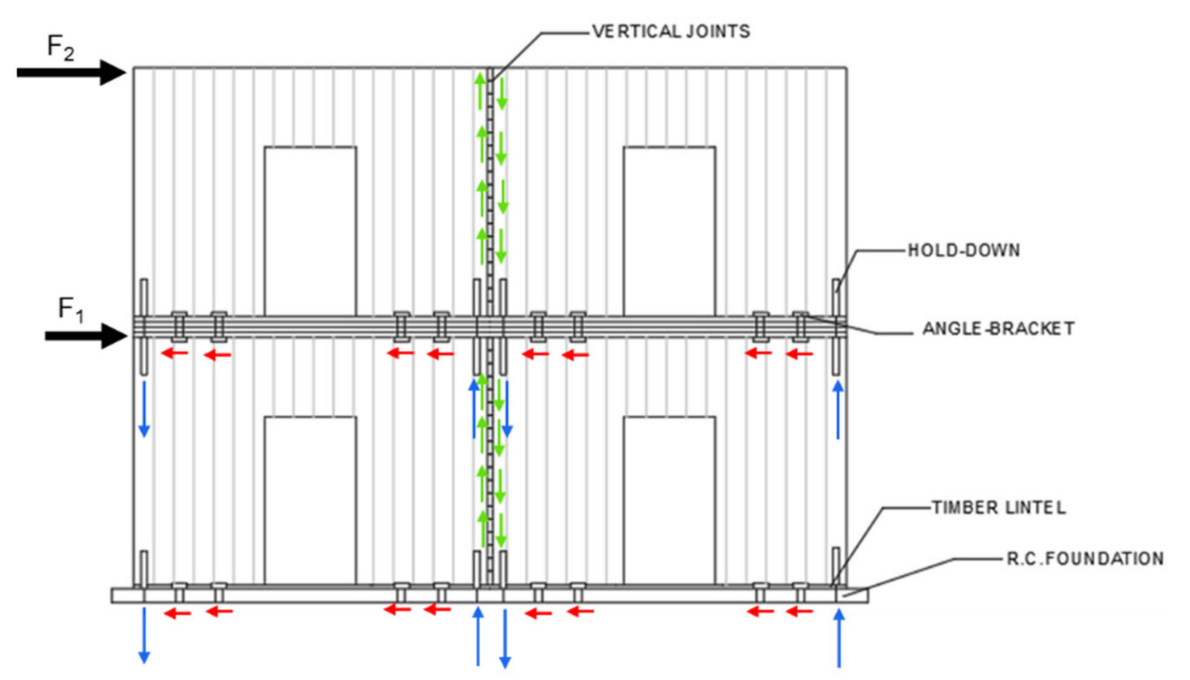

Figure 6. Seismic action paths for a CLT shear-wall.

A full box-like behavior of the construction is achieved if CLT floors are sufficiently rigid in own-plane. This assumption could be compromised (and then requires verifications) especially in the case of a floor realized by adjacent panels connected by screws. The relative elastic sliding which occurs among the panels in the joined zones could make the floors not adequately rigid in the horizontal plane; this produces a transferring of seismic actions among the seismic-resistant walls as a function of their tributary area, encouraging potential out-of-plane behavior of the vertical panels themselves. In any case, this phenomenon can be prevented by stiffening the floor by means of reinforced concrete slabs connected with steel fasteners to the timber panels. On the contrary, in the case of high-intensity earthquakes, the dissipation in the panel-to-panel connections of the floors could lead to many issues such as the amplification of higher modes of vibration and increased structural damage. For these reasons it is suggested to design the floors as non-ductile elements, with overstrength connections [18].

\subsection{Role of the Mechanical Connections}

Mechanical connections in CLT structures can be divided in two groups. The first refers to connections selected to prevent rocking (HD) and translation (AB) of the vertical panels. The second includes small diameter metal fasteners used for vertical joints in segmented walls, or for panel to panel connections of the floors, or for floor to wall connections.

To date, only HD and $\mathrm{AB}$ placed in panel to panel and in panel to foundation connection zones-and vertical joints in segmented walls—are considered as potential dissipative fuses against seismic actions. Experimental tests highlighted that in the majority of cases ductile failure modes defined by the Johansen's theory [39] have occurred for HD and $\mathrm{AB}$ loaded in tension and in shear, respectively. These mechanisms are characterized by a combination of progressive embedding of the wood and cyclic yielding of the steel fasteners (nails or screws) with a good hysteretic behaviour. 
Extensive programs aimed at investigating the cyclic behaviour of $\mathrm{HD}$ and $\mathrm{AB}$ have been conducted, for instance within the SOFIE [21] and SERIES [40] projects. Gavric et al. [21] investigated cyclic behaviour of $\mathrm{HD}$ and $\mathrm{AB}$ under different loads configuration: $\mathrm{HD}$ subjected to tension, $\mathrm{HD}$ subjected to shear, $\mathrm{AB}$ subjected to shear and $\mathrm{AB}$ subjected to tension. Test results demonstrated that $\mathrm{HD}$ tested in tension show high strength and stiffness in their primary direction (tension), while in shear direction they do not achieve high strength and stiffness due to local buckling of steel plates. $A B$, instead, have significant strength and stiffness in both directions. Cyclic response of $\mathrm{HD}$ is characterized by wide loops in tension and null in compression, while $\mathrm{AB}$ have a hysteretic response with pinching due to the slip of the fasteners in the embedded holes of the wood. In Figure 7 are reported the forcedisplacement diagrams relative to $\mathrm{HD}$ and $\mathrm{AB}$ loaded in tension and in shear, respectively. Other similar experimental campaigns finalized to evaluate the mechanical behaviour of connections used in low and mid-rise CLT buildings have been conducted in [41-43], in which the same results have been achieved.

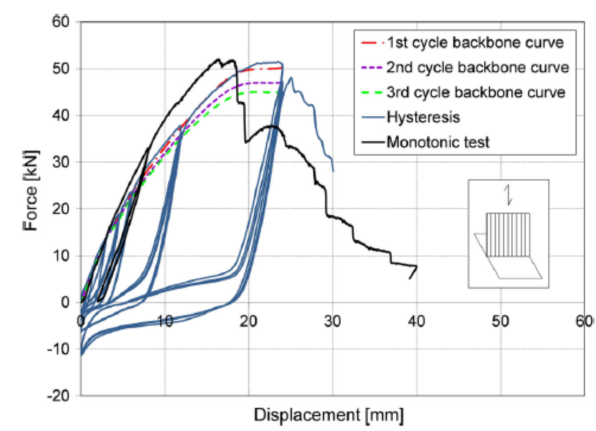

(a)

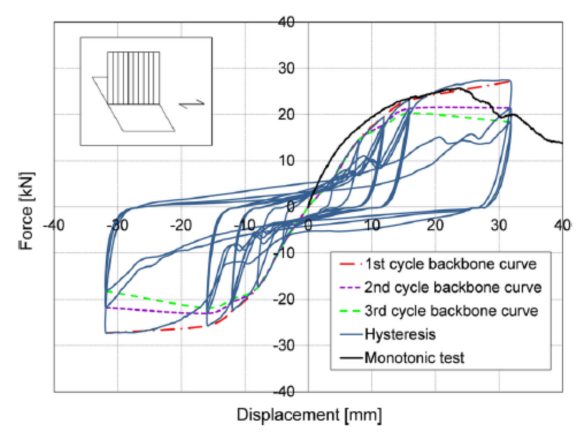

(b)

Figure 7. Typical experimental cyclic force-displacement behaviour of traditional connections: (a) hold-down loaded in tension, (b) angle-bracket loaded in shear (from [19]).

Although in design practice it is commonly assumed that $\mathrm{AB}$ carry-out shear forces and $\mathrm{HD}$ tension forces only, a simultaneous presence of shear-axial interaction occurs during an earthquake. The coupled shear-to-tension behaviour for HD [44] and AB [45] have been also investigated. Results proved that when $\mathrm{HD}$ and $\mathrm{AB}$ connections are subjected to significant combined shear and axial loads, the global ductility and dissipative capacity of the entire wall panels assembly can be significantly deteriorated.

\section{Modeling Strategies of the Components}

\subsection{Material Modeling}

In solid mechanics, CLT panels have a complex anisotropic behaviour. For structural applications (i.e., at macroscale level) the panels can be schematized as an orthotropic multi-layer material with different in-plane and out-of-plane behaviour.

Due to its strength and stiffness, the in-plane displacement capacity of shear-walls depends almost exclusively on the deformability induced by the mechanical connections, thus the CLT panel is often supposed to behave as an infinitely rigid body. On the contrary, in the case of floors the transverse layers induce significant shear deformations and influence significantly their out-of-plane flexural deflections and vibrations under service loads. Such differences of behaviour between in-plane and out-of-plane require differentiating the structural modelling of the panels in the two planes.

\subsubsection{In-Plane Modeling}

The cross-layered morphology of CLT panels and the presence of an uneven number of layers involve higher strength and stiffness in the longitudinal direction than in the transversal one. Experimental tests and numerical analyses proved that the in-plane displacement capacity of single or multi-story CLT shear-walls is dominated by rocking 
and translation contributions due to connections, while the own bending and shear deformabilities of the material are negligible because they influence by less than $5 \%$ the total plastic horizontal displacement at the top of the panel. [46,47]. Anyhow, a refined model to estimate the in-plane deflections for single and coupled CLT walls under horizontal loadings is presented in Shahnewaz et al. [37], in which also the influence of orthogonal walls and floors has been taken into account.

Macroscale models used in literature to schematize the CLT shear-walls are the homogenized orthotropic material (HOM) or the homogenized isotropic material (HIM), and their employment depends on the possibilities offered by the used finite element software. The first approach, more sophisticated, simulates the elastic properties of material (Young's, tangential and Poisson's moduli) in the longitudinal and transverse layers based on the theory of orthotropic membrane and is suitable for studies aimed at investigating the local behavior of the material.

For design practice, i.e., when the influence of material deformability is not of paramount importance, Blass and Fellomoser [48] proposed adopting HIM simplified model. It consists of reduction of a multi-layer to a single-layer section by means of the coefficient $\mathrm{k}_{3}$ and $\mathrm{k}_{4}$ (as a function of longitudinal or transversal direction of the panel) listed in Table 2. A further simplification of the HIM method has been introduced in $[49,50]$ that consists of reducing Young's modulus of raw material as a function of the effective number of layers (Table 2). Moreover, in the second method also tangential elastic modulus is suggested to reduces as a function of the effective number of layers, as for Young's modulus. When the lamellae of the panels are not glued edge to edge a further reduction of $10 \%$ of the Young's modulus is advisable, as suggested in [20].

Table 2. Coefficients for effective stiffness for cross-lam panels loaded in-plane.

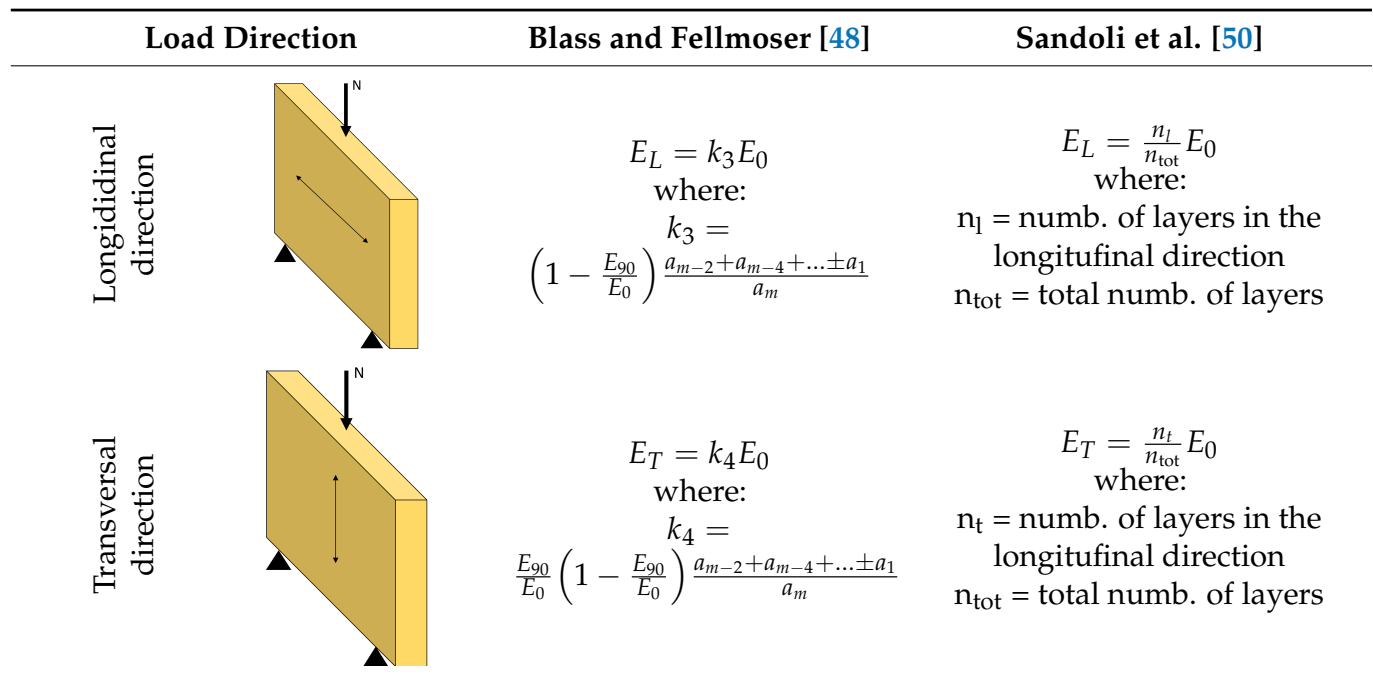

$\mathrm{a}_{\mathrm{m}}=$ panel total thickness, $\mathrm{a}_{1}=$ thickness of the middle layer, $\mathrm{a}_{\mathrm{m}-2}=$ distance between two transverse layers (measured between the center of gravity of each layer), $\mathrm{E}_{0}=$ Young's modulus of raw material.

\subsubsection{Out-of-Plane Modeling}

The out-of-plane flexural behaviour of CLT panels is significantly influenced by the shear deformations of the transverse layers. This phenomenon, indicated as "rolling shear", is due to the tangential stresses $(\tau)$ acting in the orthogonal to grain direction within transverse layers of the panels. Due to the low value of the shear or tangential modulus in the orthogonal to grain direction of timber boards (named rolling shear modulus $-G_{R}$ ), grains rolling off one from each other occur in transverse layers (Figure 8). As a consequence, increases of deflections and vibrations of the panel and modification of its internal stresses arise [51,52]. 


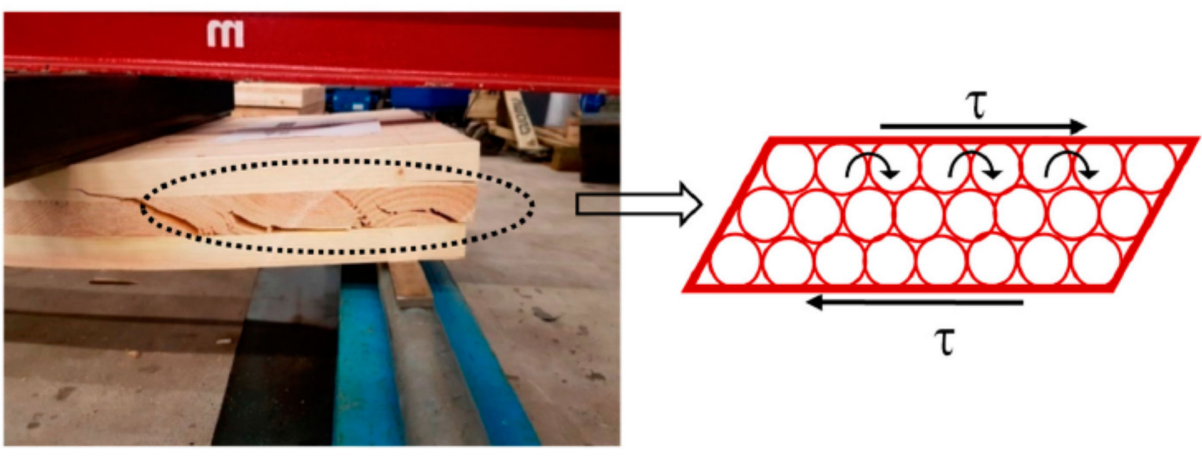

Figure 8. The "rolling shear" effect in CLT panels subjected to out-of-plane flexure.

The rolling shear phenomenon was first raised by Blass and Fellmoser [51], who highlighted its effect on the flexural behaviour of CLT floors having different length-todepth aspect ratios. Experimental studies aimed at investigating different aspects have been conducted [53-56], as well as numerical investigations. A multi-scale finite element model accounting for the rolling shear failure by means of an homogenization and cohesive zone model of the panel has been proposed by Saavedra Flores et al. [57]; such a model is able to capture the interlaminar and inter-fibre cracking and to solve the macroscopic equilibrium using computations. Strurzenbecher et al. [58] investigated the structural design and modelling by advanced plates theory which combines accuracy of the description of deformations and stresses in the plate with computational efficiency, and compared the results with analytical solutions.

Consequently, practical tools for engineering applications aimed at evaluating deflections affected by the rolling shear have been proposed in literature, and part of them has been included in manuals or guidelines [2,11]. These models are based on the beam theory, but take into account shear deformations in transverse layers. For instance the " $\gamma$-method" (also included in Eurocode 5) allows consideration for composite beams joined by metal fasteners, where the transverse cross-layers in CLT are considered as equivalent shear fasteners uniformly distributed over the length of the panel. In Table 3 are reported the formula for evaluating the effective flexural stiffness (EI) $)_{\text {eff }}$ of the panels through the coefficient $\gamma$ which takes into account the shear deformations in the transverse layers.

Table 3. Analytical formulas to evaluate the out-of-plane stiffness of CLT panels.

\begin{tabular}{ccc}
\hline Stiffness-Type & $\gamma$-Method & Shear Analogy Meth. \\
\hline & $(E I)_{e f f}=\sum_{i}(E I)_{i}+\sum_{i}\left(\gamma E A a^{2}\right)_{i}$ & $(E I)_{e f f}=(E I)_{A}+(E I)_{B}$ \\
Flexural stiffness & $\gamma=\left[1+\frac{\pi^{2}(E A \Delta z)}{\left(k l^{2}\right)}\right]^{-1}$ & $(E I)_{A}=\sum_{i}(E I)_{i}$ \\
& $k=\frac{G_{R} B}{h} \Delta z$ & $(E I)_{B}=\sum_{i}\left(E A a^{2}\right)_{i}$ \\
Shear stiffness & is taken into account trought the & $(G A)_{B}=\frac{B a^{2}}{\left[\frac{h_{1}}{2 G_{1}}+\sum_{i=2}^{n-1} \frac{h_{i}}{G_{i}}+\frac{h_{n}}{2 G_{n}}\right]}$ \\
& coeffieicent $\gamma$ &
\end{tabular}

$\mathrm{E}=$ Young's Modulus, $\mathrm{G}=$ shear modulus, $\mathrm{G}_{\mathrm{R}}=$ rolling shear modulus, $\mathrm{I}=$ moment of inertia, $\mathrm{A}=$ cross section area, $\mathrm{a}=$ distance between the centre of gravity of the single layer and the total one, $\mathrm{k}=$ equivalent stiffness provided by transverse layers, $\mathrm{l}$ = panel length, $\mathrm{B}=$ panel width, $\mathrm{h}=$ panel height.

Another method is the "shear analogy method" introduced by Kreuzinger [59]. Therein, the effective flexural stiffness (EI) eff and the shear stiffness (GA) are assigned to two displacement-coupled beams: Beam $\mathrm{A}$ is given by the sum of the inherent flexural and shear stiffness of the individual layer along its own centres, while beam $B$ is given by the Huygens-Stainer points, or an increased moment of inertia because of the distance from the neutral axis of the flexural and shear stiffness of the panel. These beams are coupled with infinitely rigid web elements in order to ensure the same elastic curvature between 
beams A and B. In Table 3 are reported the formulas for calculating flexural and shear stiffness trough the "shear analogy method".

A comparative analysis between these two methods, carried out on panels with lengthto-depth rations from 5 to 50 , has been recently presented in [52]. The authors concluded that for ratios ranging from 25 to 40 (typically used in CLT buildings) the results given by the " $\gamma$-method" and the "shear analogy method" are comparable, either in terms of deflections and internal stress state of the panels.

\subsection{Connection Modeling}

As mentioned, in design practice the in-plane flexural behavior of CLT shear-walls is ruled by rocking and translation due to connections. Thus, to evaluate the flexural load-bearing capacity of the panel, an adequate modeling of the connections is of paramount importance.

The majority of methods presented in literature assume that the panel to panel and the panel to foundation are modelled in analogy with reinforced concrete cross-sections. The HDs represent the tensile-resistant elements (e.g., steel bars), ABs are the shear-resistant elements (e.g., stirrups), while timber to timber contact represents the concrete in the compressed zone (this latter is defined by a neutral axis depth).

Two different groups of methods can be defined: (a) simplified and (b) detailed. In the first case the contribution of timber in the compressed zone is disregarded, while in the second case it is considered. A simplified mechanical model to evaluate the in-plane flexural load-carrying capacity of CLT panels has been proposed in [60]. It is based on the equilibrium between the internal forces developed by HD and the overturning moment, assuming that the panel rotates around its edge and that the tensile stress distribution at the base cross-section of the panel is linear (Figure 9a). Gavric and Popovski [61], instead, refined the methodology proposed in [60] considering also the possibility of the shear to tension interaction in the connectors, and in particular in the ABs as tests showed that HDs do not provide significant shear resistance.

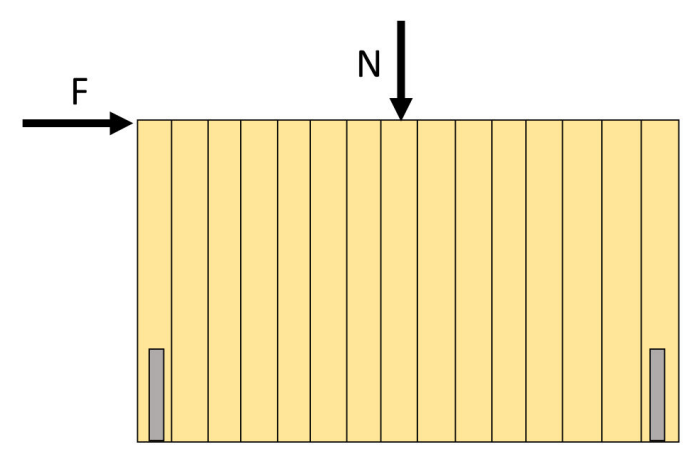

a)

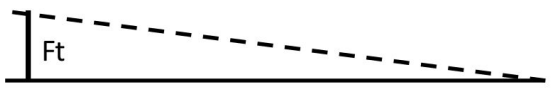

b)

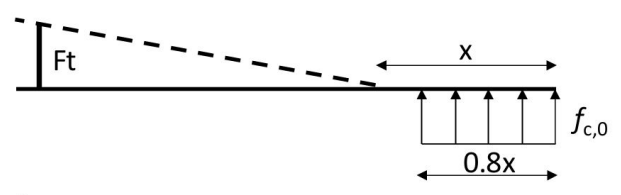

c)

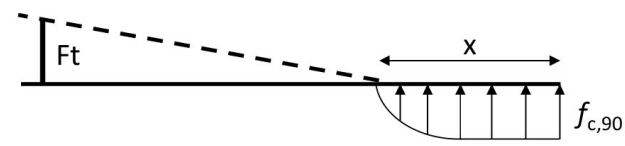

Figure 9. Assumption on normal stress distributions at a pane to panel and panel to foundation contact. 
Pei et al. [62], introduced another simplified method based on a linear tensile stress distribution again, but the connector's elongation and its stiffness and strength are considered. The tensile strength of each connector is proportional to the distance of the connector from the panel edge. A triangular distribution of the connector displacement is considered based on the fact that the furthest connector reaches its total elastic tensile strength.

The timber to timber or timber to foundation compression strength in evaluating the load-carrying capacity of CLT panels has been considered in [63]. Herein, the compressed zone is modelled by means of a stress-block diagram with maximum design strength equal to that of timber in parallel to grain direction $\left(\mathrm{f}_{\mathrm{c}, \mathrm{O}, \mathrm{d}}\right)$ (Figure $9 \mathrm{~b}$ ). An advancement of this method is presented in [64], where both elongation capacity of connection elements and the compressed timber contribution are considered. In particular, the maximum compression strength in parallel to grain direction and the Young's $\left(\mathrm{E}_{90}\right)$ modulus in orthogonal to grain direction have been adopted for the compressed timber in the case of timber to timber contact; while for timber to (reinforced concrete) foundation contact the Young's modulus $\left(\mathrm{E}_{0}\right)$ in parallel to grain direction has been assumed.

A further study recently developed in [50] proposes a theoretical model which includes both orthogonal to grain compression strength $\left(\mathrm{f}_{\mathrm{c}, 90}\right)$ and orthogonal to grain Young' modulus for timber to timber contact (while $E_{90}$ and $f_{c, 90}$ are changed with $E_{0}$ and $f_{c, 0}$ in the case of timber to concrete contact at the foundation) (Figure 9c). A parabola-rectangular stress $\left(\sigma_{\mathrm{c}, 90}\right)$-strain $\left(\varepsilon_{\mathrm{c}, 90}\right)$ model has been proposed (using the relationships proposed by Eurocode 2 for the concrete) to model the compressed timber in orthogonal to grain direction.

Such methods remain also valid in the case of coupled walls, provided that the contribution of the vertical joints is included in the evaluation of the flexural strength of the panels. Simplified model which do not consider the compressed timber contribution can be found in [47], while in [49] the panel to panel orthogonal to grain compression stresses have been also included in the model.

In a recent study, Franco et al. [65] introduced the effect of shear to axial force interaction on the flexural capacity of CLT panels. They adopted an elastic-perfectly plastic constitutive law for timber and coupling effect between the axial and lateral strength of the connections, allowing for a more realistic representation of the flexural behaviour of the panels.

\section{Modeling of Multi-Story Timber Buildings}

The adoption of finite element numerical models for multi-storey CLT buildings became of particular importance in both the research field and design practice. The execution of full or reduced-scale tests is expansive and time consusming procedure because of the several parameters that affect the seismic behavior of CLT shear-walls. Thus, the availability of reliable numerical models makes it fundamental for engineers to perform both linear and non-linear seimic analyses. With this aim, different finite element methods, more or less simplified, for multi-story CLT buildings presented in literaure are discussed in the following sections.

\subsection{Vertical Walls}

The in-plane behavior of CLT multi-story shear-walls is generally modelled througth 2D-shell elements, whose material elastic properties are calculated with one of the methods described in Section 4.1.1. Nevertheless, alternative approaches are available in literature: for instance a set of trusses (pinned in the corners) with a diagonal truss or springs simulating the in-plane strength and stiffness of the panels [66,67]. With respect to 2D-shell models, truss elements cannot make visible the whole stress path in the panel but only the resultant of the internal forces in the elements, resulting in being less effective in the case of walls with openings. In fact, it has been proved that, in the case of perforated walls, a stress concentration in the corners at the interfaces between lintels and vertical panels can arise. Such stresses can be higher than the design strength values of material and lead to local brittle failure of the material in the corner region due to tension or compression $[23,50,68]$. 
Furthermore, also in case of segmented walls having lintels connected by means of metal fasteners to the adjiacent vertical panels, brittle failure modes due to stresses concentration in the corners can precede the ductile mechanisms of the connections [20].

Another sophisticated model based on the use of 3D-solid elements which considers both thickness of the panels and layer orientation of the boards has been presented in [69].

Particular attention should be paid in modeling of perforated walls, because they are affected by the lintels. As discussed in Section 3.1, the lintels may have a different lay-out depending on how the wall is conceived, as a monolithic or segmented. In the monolithic case, the number of effective vertical layers against flexure and shear forces is less than that in the vertical panels (Figure 10a). On the contrary, in the case of segmented walls the lintels can have the same number of effective layers of the vertical panels (Figure $10 \mathrm{~b}$ ). In this latter case the lintels can be (i) less or more effectively fastened to the adjacent vertical panels by means of metallic fasteners or (ii) simply supported on adjacent vertical panels (without fasteners).

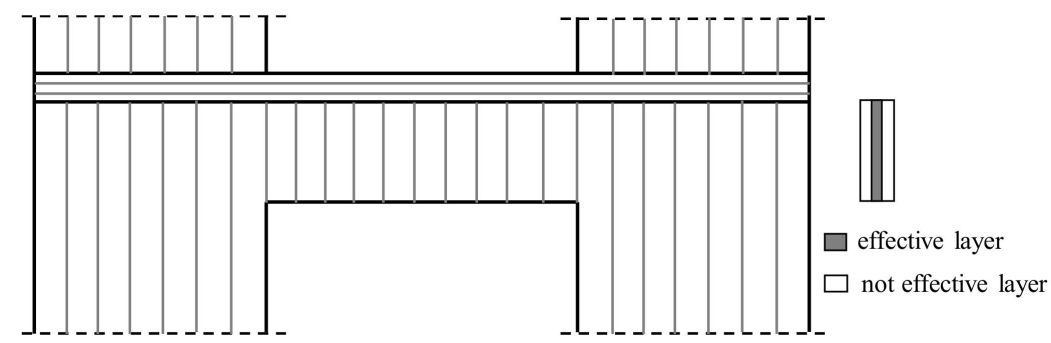

(a)

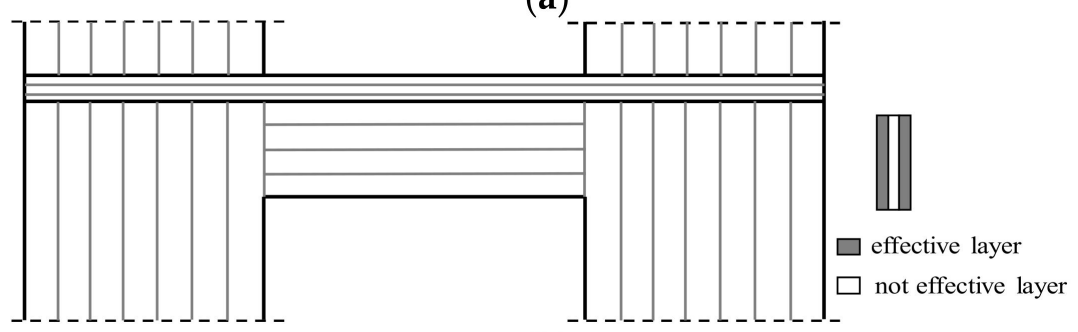

(b)

Figure 10. Lintels configurations in case of: (a) monolitich wall, (b) segmented walls.

The seismic behavior of CLT walls with opening is also affected by the relative stiffness of the mechanical connections at the base of the panels with respect to the in-plane stiffness of the wall (and the lintels). Such an issue has been investigated in Mestar et al. [70], where a kinematic model to analyze the effect of different hold-down configurations on the overall in-plane stiffness has been developed, and the results obtained compared with the experimental ones. They concluded that the degree of coupling decreases with increased hold-down stiffness and increases with wall segment width.

\subsection{Floors}

As well as for the shear-walls, the in-plane behavior of CLT floors can be schematized with 2D-shell elements having material properties calculated as descibed in Section 4.1.2, or through truss elements having diagonals (made with trusses or springs) to simulate the in-plane strength and stiffness of the floors [71,72].

Lateral force transferring a diaphragm represents a topic still under study by reserchers, then few indications can be found in both research papers and codes. For practical purposes, CLT floors are assumed as rigid diaphragms in the finite element model of the buildings: they are capable to transfer horizontal seismic actions to the vertical walls, provided that panel-to-panel connections are suffciently stiff and resistant.

The assumption of a rigid diaphgram is of particular importance in seismic analyses, because flexibility of floors can influence the fundamental vibration modes of the structures 
changing the force transmission on the vertical elements [71]. When such an assumption is made, NDS [33] suggests verifying it by calculating the maximum in-plane deflection of the floors. For a simple supported floor, having length $\mathrm{L}$ and width $\mathrm{W}$, maximum deflection can be deermined as in the following (Figure 11):

$$
\delta=\frac{5 v L^{3}}{8 E A W}+\frac{w L^{2}}{8 A_{c l t} G_{e f}}+C L e_{n}+\frac{\sum\left(x \Delta_{c}\right)}{2 W}
$$

L
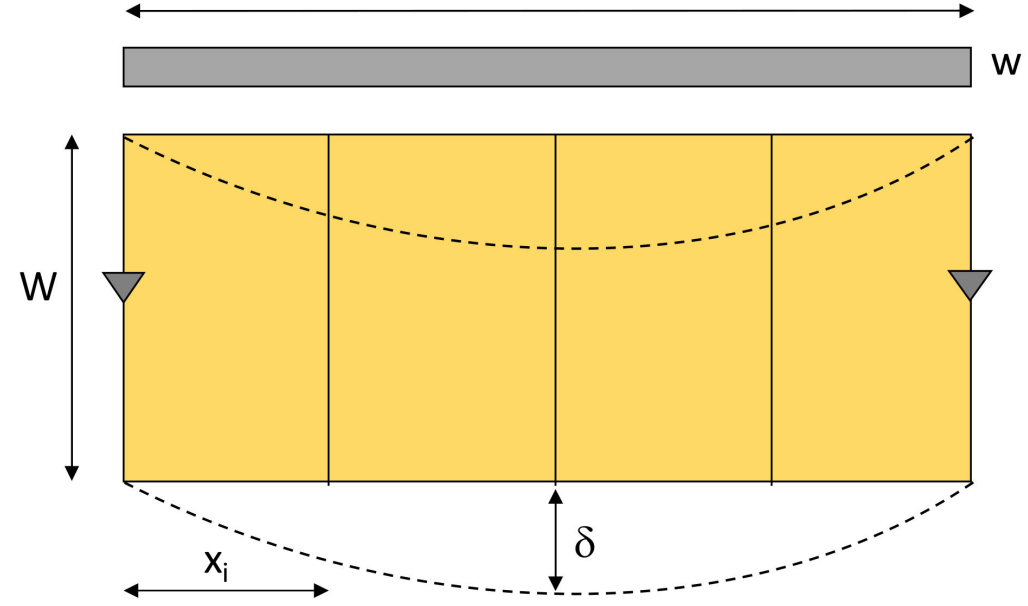

Figure 11. In-plane deflection of CLT floors under seismic actions.

The first term of the Equation (1) represents the flexural deflection contribution, where $\mathrm{v}=\mathrm{wL} / 2 \mathrm{~B}$ is the maximum shear at the edge of the diaphgram calculated from the uniformly distributed load w, B is the diaphragm width, E is the Young modulus and $\mathrm{A}$ the cross-section area of the effective lamination layers. The second term is the shear deformation of the CLT panels, where $A_{c l t}$ is is the gross cross-sectional area of the CLT diaphragm resisting the shear load and $\mathrm{G}_{\mathrm{ef}}$ is the effective shear modulus; this latter can be estimated as in Flaig and Blass 2013 [73]. The third term takes into account the slip contribution of the connection on the total deflection: the value of $C$ is calculated as $\mathrm{C}=0.5\left(1 / \mathrm{P}_{\mathrm{L}}+1 / \mathrm{P}_{\mathrm{W}}\right)$ where $\mathrm{P}_{\mathrm{L}}$ and $\mathrm{P}_{\mathrm{W}}$ represent the length and the width of the typical panel respectively, while $\mathrm{e}_{\mathrm{n}}$ is the connection slip at the outer edge of the diaphgram under the maximum shear load v. The derivation of $e_{n}$ can be found in the ATC-7 [74], derived for application to typical wood structural panels diaphgrams. The fourth term is the geometric translation of any chord slip under loading into lateral deformation of the diaphragm, where $\Delta_{\mathrm{C}}=2$ (Tor $\mathrm{C}$ ) $/ \gamma \mathrm{n}$ ( $\mathrm{T}$ and $\mathrm{C}$ are the maximum tensile and compression forces due to applied loads $\mathrm{w}, \gamma$ is the load slip modulus and $n$ the number of fasteners) and $x$ is the length considered for evaluating maximum deflection due to chord slip.

By contrast, when the floors are modelled by means of 2D-shell elements or trusses the maximum in-plane deflection can be determined as a result of the numerical analyses.

As regards the schematization of the out-of-plane behavior, it is limited to evaluate the amount of the out-of-plane flexural deflections or vibrations. Literature papers demonstrated that the analytical model described in the Section 4.1.2 gives back reliable results to calculate flexural deflections, vibrations and stress state, comparable with those obtained with finite element models composed of multi-layer material [52]. In any case, the adoption of the multi-layer material surely gives back more consistent results and allows conducting modal analyses to calculate accurately maximum vibrations.

\subsection{Mechanical Connections}

In multi-story CLT buildings the mechanical connections are usually modelled through links, trusses or frame elements. 
According to literature, uniaxial or biaxial behavior is generally considered to simulate the connections [23,46,50,75-77]. In the first case, HDs and ABs resist only in their primary direction (e.g., HDs only in tension and ABs only in shear), in the second case both HDs and ABs resist axial and shear forces simultaneously. Uniaxial behavior is commonly used in the practical applications and leads to more conservative results with respect to the biaxial behavior. Moreover, for detailed analyses (e.g., time history analyses) the tension to shear force interaction domains are available to model the biaxial behaviour [61].

The models discussed in Section 4.2 are used to schematize the panel to panel and the panel to foundation connection zones in finite element models of multi-storey CLT buildings. Both 'simplified' or 'detailed' approaches discussed can be used to model the connection regions. Simplified methods do not consider the timber to timber contact contribution, then the connection model consists of: (a) HD truss or spring elements, which simulate the tensile behaviour of the hold-downs devoted to face tensile forces due to rocking of the panel; (b) AB truss or spring elements, which simulate the angle brackets devoted to resist shear forces due to translation of the panel. In such a model HD and AB are modelled as no-compression elements (due to buckling phenomena of the stem of HDs not interested by fasteners, when subjected to compression forces).

To obtain more realistic analytical results, the contribution of the compressed timber should be included in the structural model. Thus, additional no-tension truss or spring elements devoted to simulate the timber to timber contact have been introduced in the structural model developed in references [50,64,75].

Three different approaches to model the non-linear behaviour of the connections, and considered as representative for this paper's purpose, are reported in Table 4. An effective but sophisticated approach to model the cyclic behaviour of the connection has been presented by Rinaldin et al. [77]. The authors proposed the adoption of multi-linear hysteretic cyclic behaviour for both HDs and ABs, implemented thought a multilinear spring placed at the base of finite element model of the wall. Such schematization allows dynamic non-linear analyses to be carried out. Instead, a simplified monotonic trilinear model implemented within non-linear springs has been suggested by Yasumura et al. [63] to carry out non-linear static analyses. Simplified elastic-perfectly plastic force-displacement behaviours have been also proposed in Vassallo et al. [76] and Sandoli et al. [50]. The first difference between these two latter models is that in Sandoli et al. [50] the timber to timber contact takes into account the orthogonal to grain timber properties, while in Vassallo et al. [76] only that in parallel to grain direction is considered. The second difference is that in Vassallo et al. [76] the shear forces are faced through a couple of diagonal trusses joined at the corner of the panel, while in Sandoli et al. [50] through frame elements.

Table 4. Literature models for connections.

\begin{tabular}{|c|c|c|}
\hline \multirow{2}{*}{ Authors } & Structural Model & Connection Model \\
\hline & \multicolumn{2}{|c|}{ Trilinear Cyclic Behavior } \\
\hline $\begin{array}{l}\text { Rinaldin et al. } \\
\text { [77] }\end{array}$ & 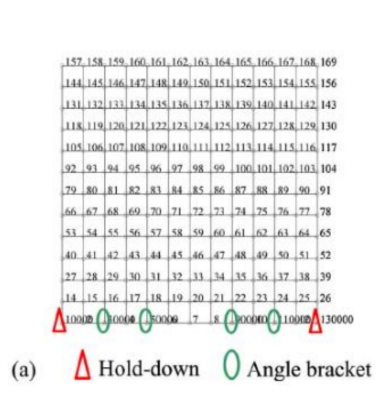 & 每) \\
\hline
\end{tabular}


Table 4. Cont.

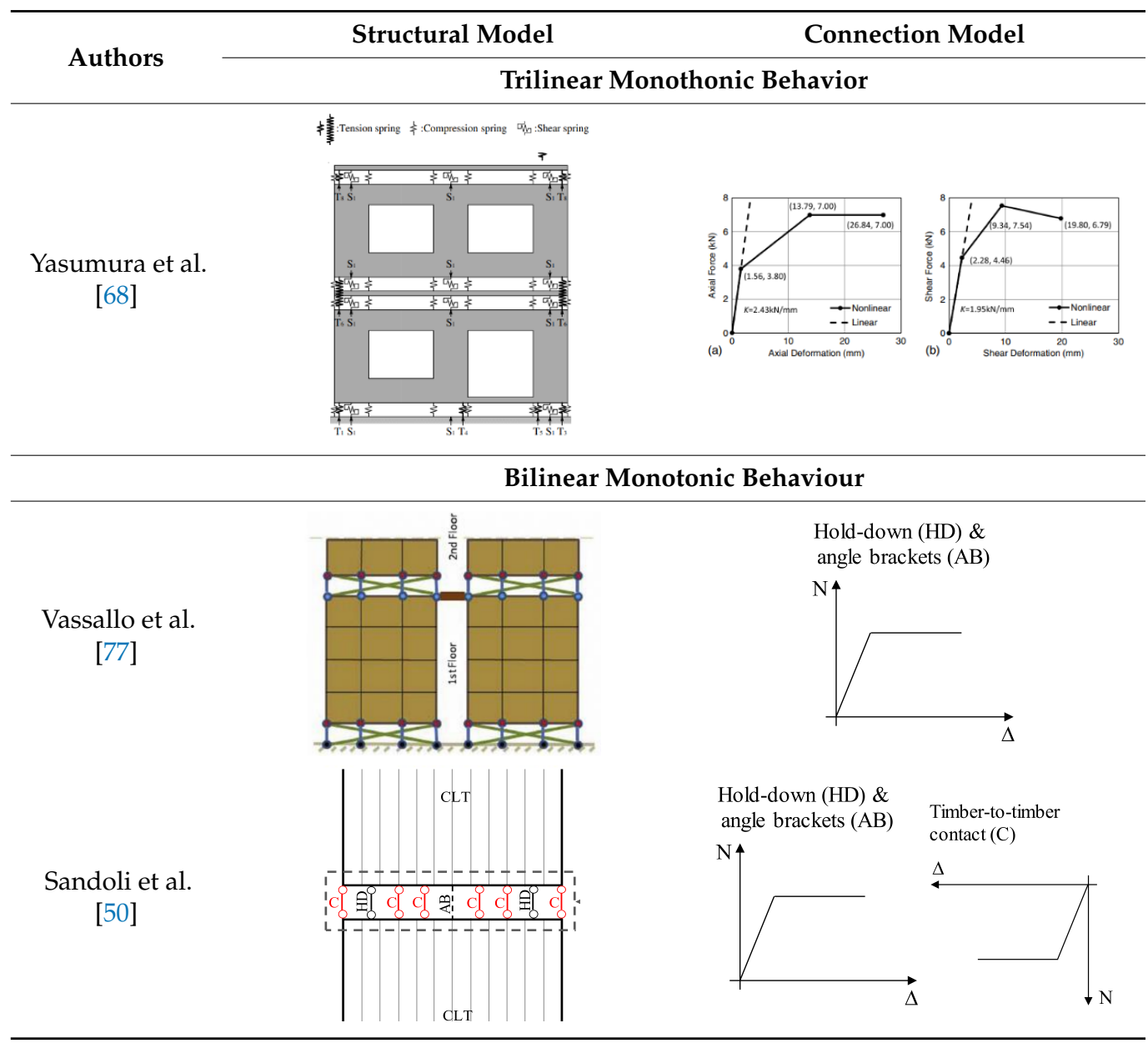

These connection models are also valid to schematize the panel to panel and the panel to foundation connection zones in the case of coupled (or segmented) CLT wall, provided that additional shear springs to simulate the shear stiffness and strength of the fasteners in the vertical joints between the panels are included in the structural model $[47,49,78]$.

\section{Future Trends in CLT Building Practices}

\subsection{Damage of the Timber Components}

The modern performance-based seismic design (PBD) method entails high-performant and high-safety structures, capable of overcoming severe earthquakes exploiting all their available strength, stiffness and ductility. Nevertheless, the reduction of (i) damaging of structural and non-structural components, (ii) economic losses after the seismic event and of the (iii) environmental impact during the entire life of the construction (including the disposal and recycling) are also required by PBD.

Experimental tests on connections highlighted serious damage in panel to panel and in panel to foundation connection zones: in spite of a ductile response of the whole connections, vertical timber panels showed diffused permanent damage after the tests due to timber embedding produced by the interaction between timber boards and metal fasteners (Figure 12), while metal connectors yield. 

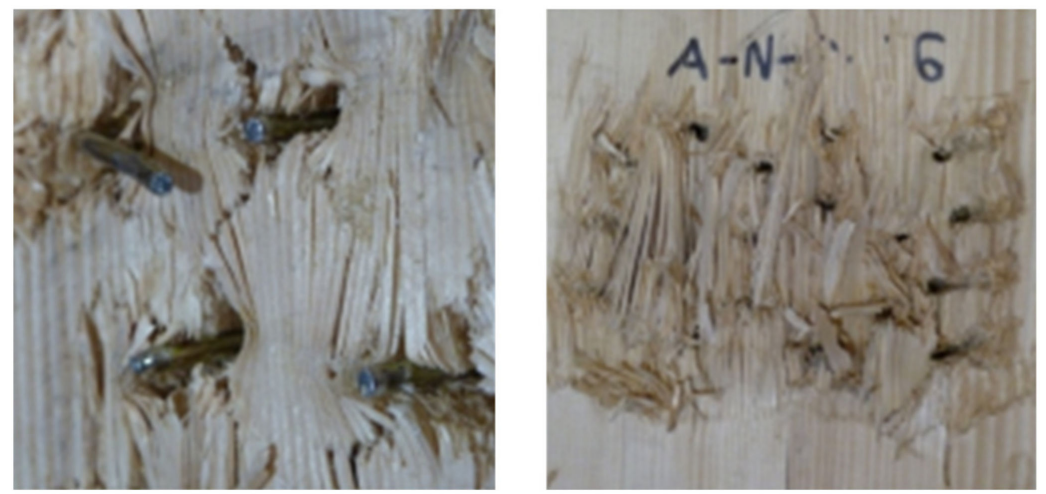

Figure 12. Damage to CLT vertical panels due to embedding.

It should be pointed out that the current design method proposed in manuals, literature papers or guidelines provided that Johansen's ductile failure modes develop in the mechanical connections (HD and AB) $[11,15,31,68,75]$. Some of these mechanisms are reported in Figure 13a-c. Sometimes ductile mechanisms have been anticipated by brittle failure modes caused (i) by the reduced end edged spacing or underestimation of the actual strength of the ductile components, with consequent increased strength demand for the brittle parts, which may fail if designed with insufficient overstrength (Figure 13d,e) [25,26]; or (ii) by high number of metal fasteners which produce the so called "group effect" (Figure 13f) [11].
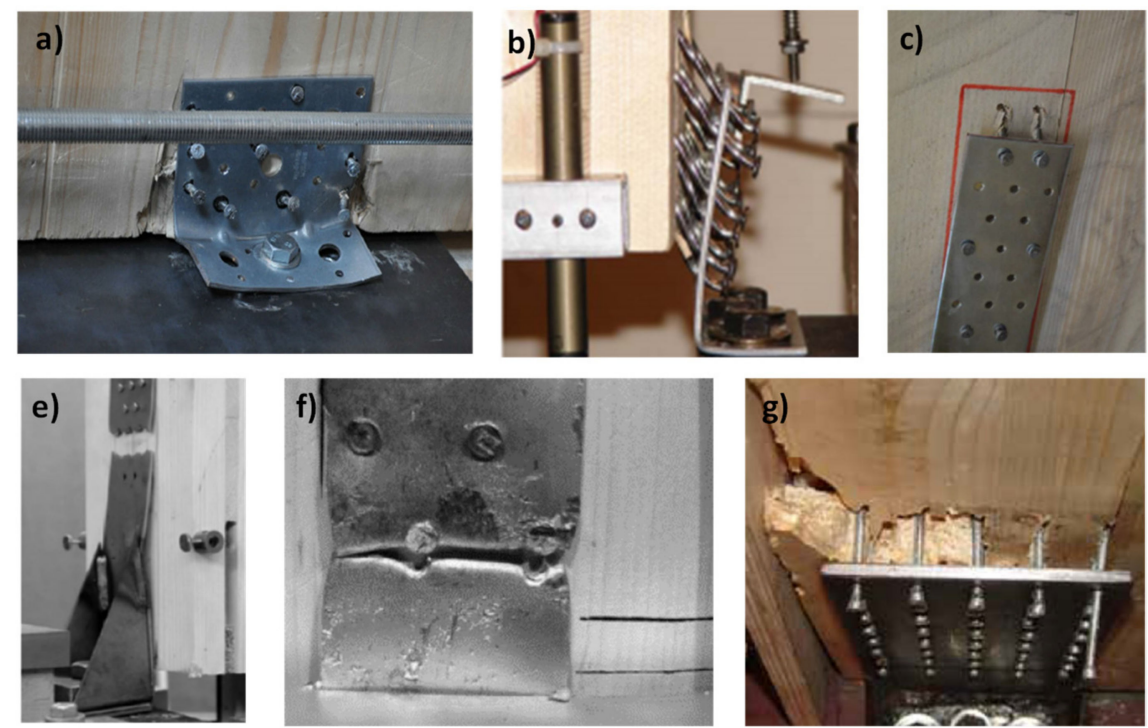

Figure 13. Typical failure modes of the traditional connections: (a) Gavric et al. [21], (b,c) Schneider et al. [79], (e-g). FP innovation handbook [11].

Subjected to seismic actions, also the horizontal panels (floors) will remain permanently damaged. The compression forces transmitted by the rocking motion of the vertical CLT panels involve an irreversible crushing of the floor panels in the timber to timber contact zones [50]. In particular, the compression forces load the floor panels in orthogonal to grains direction, where low strength and stiffness of material is expected $\left(\mathrm{f}_{\mathrm{c}, 0} / \mathrm{f}_{\mathrm{c}, 90} \cong 10\right.$, $\mathrm{E}_{0} / \mathrm{E}_{90} \cong 30$ ).

Therefore, both vertical and horizontal panels will be unusable after a seismic event, as well as the entire construction, with considerable economic losses and environmental impact as replacing materials timber and steel increases the carbon dioxide release in the atmosphere.

In the last few years, "integrated design" approach between seismic performance and environmental sustainability attracted researchers' attention. The key concept is that 
sustainability means not only ensuring the best heating and cooling energy consumption of the buildings with respect to the seasonal cycles but also guaranteeing optimal seismic behaviour with regard to damage reduction in the structural (and non-structural) elements.

\subsection{New Frontiers for More Sustainable CLT Structures}

It is recognized that CLT buildings are provided with high environmental sustainability during their life cycle, with respect to other structural types (e.g., reinforced concrete). This depends, firstly, on the excellent eco-sustainability attitude of raw material and, secondly, on the attention paid by the manufacturers to produce certified environmentally sustainable materials.

The sustainability of CLT buildings can be furtherly enhanced within the life cycle of the construction if the amount of material disposal and/or its recycling is reduced. Seismic damage to timber parts is one of the main causes of material disposal and recycle, and it appears fundamental to mitigate seismic damage in the connection zones.

In order to reduce damage in timber panels, some alternative connection systems have been recently introduced in literature. The common goals of such systems are those of:

- concentrating the hysteretic behaviour in metal parts (i.e., steel plates or similar devices) only;

- $\quad$ eliminating possibilities of damaging in timber components (both timber embedding of CLT vertical panels and orthogonal to grain crushing of horizontal ones).

To satisfy these requirements, a new way of conceiving the connection zones is needed. The current hierarchy of strength criterion based on the concept of the strength of metal plates-weak timber to steel connections (i.e., timber to fasteners interaction) should be inverted as strong CLT panels-weak metal devices. To obtain this, cyclic dissipation must be concentrated in steel devices properly conceived as regards this aim.

Such solutions are recognized as low-damage connections. They represent an innovative aspect in timber buildings practice, even if they arose in the United States in the 1990s for post-tensioned precast concrete structures [80] and subsequently were adapted in New Zealand to post-tensioned rocking timber structures [81,82]. Dissipative connections proposed in New Zealand consist of fuse-type elements made with mild steel (or viscous damping) dissipaters placed at the base of the panels, replaceable after seismic damaging (reason for which are also named "plug and play" systems) (Figure 14).

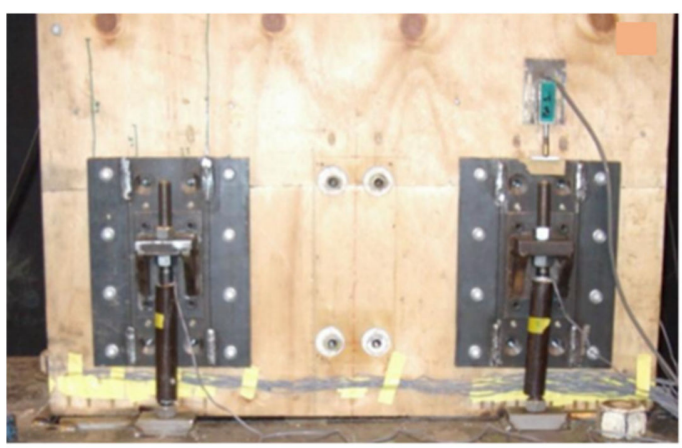

Figure 14. Plug and play fuse-type external dissipaters (from [82]).

A low-damage philosophy can be also applied to the traditional CLT buildings, adopting connection systems devoted to hysteretic energy dissipation similar to those used for post-tensioned structures. The main objective is that under seismic actions the vertical timber panels remain elastic and undamaged, thus they can be reused to attach new connections after seismic damage. With respect to traditional $\mathrm{HD}$ and $\mathrm{AB}$, the low-damage connections rely on the dissipation of steel part only, with further advantages: cyclic behaviour presents wide loops without pinching and strength and stiffness degradation is that of steel. 
Replaceable connections can be made with mild-steel bars, or thin steel plates nailed or screwed to timber panels having a properly designed shape. For instance, Latour and Rizzano [25] proposed a new type of hold-down called the XL-stud, where the main idea is to shift the dissipative zone of the hold-down from the stem zone to the flange plate (Figure 15a). The stem zone has to be over-strengthened by adopting a proper number of nails and by checking the resistance of stem and wood with respect to the force needed to yield the flange plate. Moreover, to maximize the plate energy dissipation, the proposal is to give an hourglass shape to the flange plate of the angle (Figure 15b).

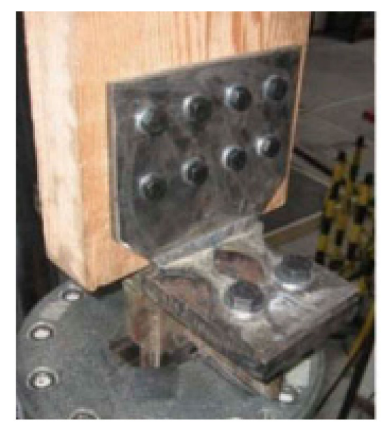

(a)

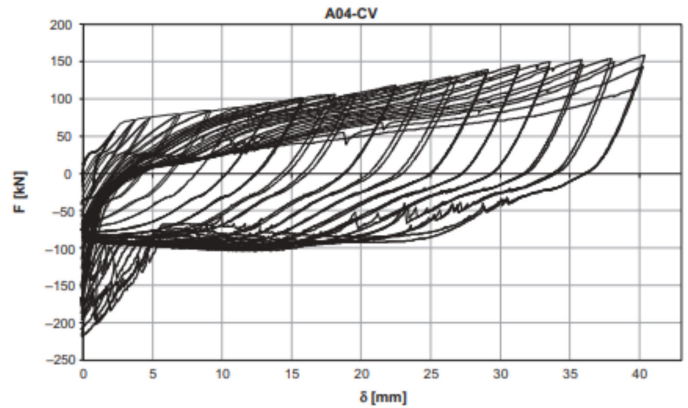

(b)

Figure 15. XL-stud connection system: (a) XL-stud shape, (b) cyclic behaviour (from [25]).

Scotta et al. [26] proposed another innovative dissipative connection (named X-bracket) composed of X-shaped metallic plates nailed or screwed to timber panels, used to withstand either tensile and shear forces in panel to panel, panel to foundation and wall to wall connections (Figure 16a,b respectively). Energy dissipation involves the steel plates only, while timber parts are overstrength. The $\mathrm{X}$-shape is optimized to prevent localized failures and to assure diffuse yielding of material, emphasizing ductility and energy dissipation capacity (Figure 16c,d).

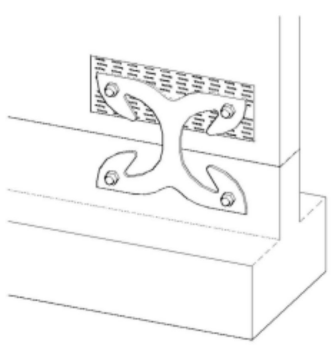

(a)

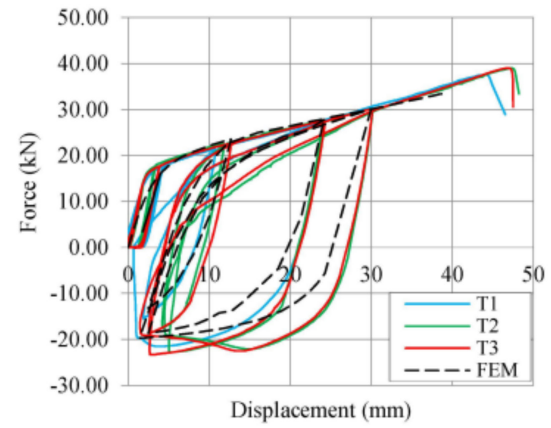

(c)

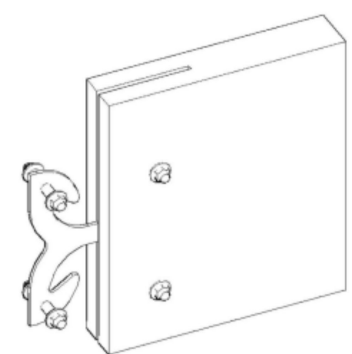

(b)

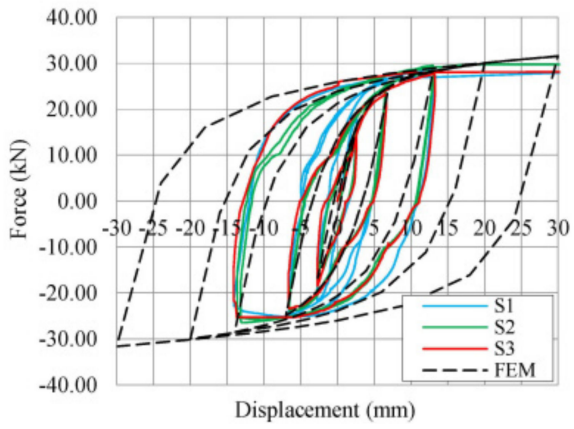

(d)

Figure 16. X-brackets connector: (a) panel to foundation connection, (b) wall to wall connection, (c) tensile test, (d) shear test (from [26]). 
The issue of damage to timber parts has been also raised in Sandoli et al. [50]. They proposed an alternative dog bone-shaped HD to perform predictive nonlinear static analyses, whilst experimental results are not still presented. As for Latour and Rizzano [25], the energy dissipation is concentrated in the stem of the HD not interested by fasteners, such that the timber-to-steel interaction remains elastic and CLT panel undamaged.

To date, there is no experimental evidence in the literature of orthogonal to grain crushing of horizontal floors due to compression forces transmitted by rocking motion of the vertical panels, nor has it been observed on real buildings hit by earthquakes. On the other hand it is evident that such damage is related to the platform constructional technology currently adopted for CLT constructions, which requires floors interposed between two consecutive vertical panels. As an alternative, a balloon-type technique permits such a problem to be overcome, because the floors are connected on the internal side of the vertical walls by means of specific mechanical connections. The balloon technique has been already used in building practice in New Zealand for low-damage timber constructions having CLT or LVL shear-walls as seismic-resistant system and timber frames to resist gravity loads. Moreover, it is comforting that studies on mechanical behavior of balloon CLT shear-walls are ongoing with regard to CLT buildings [38].

\section{Conclusions and Outlooks}

This paper reports a state-of-the art overview on seismic performance and sustainability aspects of CLT buildings in seismic-prone regions. In general, the growing interest of traditional CLT buildings, i.e., realized with a platform construction technique and connection made with hold-downs and angle-brackets, for the residential and non-residential construction market has been remarked upon in the paper.

Such development is mainly due to the high sustainability of material on the whole life cycle (from extraction of raw material, to production and usage, up to disposal and recycle). Despite the fact that no observations on the behavior of seismically-designed CLT buildings hit by real earthquakes are available to date, experimental and numerical studies highlighted the particular attitude of CLT buildings to withstand severe earthquakes thanks to lightness of material and to significant dissipation capacity of the connections. Numerous experimental tests on traditional connections (or subassemblies) and modelling methods for multi-story CLT buildings subjected to seismic actions have been proposed in literature. Such methods, giving reliability and easy application to engineers, are still not reflected in national or international design codes.

The state-of-the-art overview allowed us also to draw conclusions on future trends in buildings practice aimed at enhancing both seismic performance and environmental sustainability.

Recognizing the basic attribute of CLT buildings to exhibit good seismic performance, it has been pointed out as the reduction of structural damage in timber components can further enhance the already high environmental sustainability in the phases of disposal and/or recycling of material. More than with other structural types, CLT buildings are particularly suitable to changes of technological and constructional details because they are characterized by the level of prefabrication. Some researchers are studying alternative (low-damage) connection systems to prevent seismic damage to vertical timber walls in the case of moderate and severe earthquakes, or alternative constructional details (balloon-type construction instead of platform-type) to prevent permanent damage to floor panels in timber to timber contact regions. The goals of such systems are, respectively, those of concentrating the hysteretic behavior in metal parts only (i.e., steel plates or similar devices) and of eliminate orthogonal to grain permanent crushing of panel floors due to the rocking motion of the vertical panels.

Although in the majority of cases only experimental results are available and any conclusive consideration can be made to date, alternative low-damage solutions seem to be reasonably effective for damage reduction in timber elements. Future advancements will 
be necessary, devoted to validating such systems with regard to technological feasibility, numerical modelling and the effectiveness of life cycle assessment.

Author Contributions: Conceptualization, A.S. and B.C.; methodology, A.S., C.C., C.D.; validation, B.C. and A.P.; data curation, A.S. and B.C.; writing—original draft preparation, A.S.; writing-review and editing, A.S., C.C., C.D. and A.P.; visualization, C.C. and B.C.; supervision, B.C. and A.P. All authors have read and agreed to the published version of the manuscript.

Funding: This research received no external funding.

Conflicts of Interest: The authors declare no conflict of interest.

\section{References}

1. Brandner, R.; Flatscher, G.; Ringhofer, A.; Schickhofer, G.; Thiel, A. Cross laminated timber (CLT): Overview and development. Eur. J. Wood Prod. 2016, 74, 331-351. [CrossRef]

2. Swedish Wood. The CLT Handbook-CLT Structures, Fact and Planning; Swedish Wood: Stockholm, Sweden, 2019.

3. Iqbal, A. Cross Laminated Timber in New Zealand: Introduction, prospects and challenges. N. Zealand Timb. Design J. 2018, $22,3-8$.

4. Pei, S.; Rammer, D.; Popovski, M.; Williamson, T.; Line, P.; van de Lindt, J.W. An overview of CLT research and implementation in North America. In Proceedings of the WCTE, Vienna, Austria, 22-25 August 2016.

5. Goto, Y.; Jockwer, R.; Kobayashi, K.; Karube, Y.; Fukuyama, H. Legislative background and building culture for the design of timber structures in Europe and Japan. In Proceedings of the WCTE, Seoul, Korea, 20-23 August 2018.

6. Chen, C.X.; Pierobon, F.; Ganguly, I. Life Cycle Assessment (LCA) of Cross-Laminated Timber (CLT) Produced in Western Washington: The Role of Logistics and Wood Species Mix. Sustainability 2019, 11, 1278. [CrossRef]

7. Borjesson, P.; Gustavsson, L. Greenhouse gas balances in building construction: Wood versus concrete from life-cycle and forest land-use perspectives. Energy Policy 2000, 28, 575-588. [CrossRef]

8. Guo, H.; Liu, Y.; Meng, Y.; Huang, H.; Sun, C.; Shao, Y. A Comparison of the Energy Saving and Carbon Reduction Performance between Reinforced Concrete and Cross-Laminated Timber Structures in Residential Buildings in the Severe Cold Region of China. Sustainability 2017, 9, 1426. [CrossRef]

9. Liu, Y.; Guo, H.; Sun, C.; Chang, W.-S. Assessing cross laminated timber (CLT) as an alternative material for mid-rise residential buildings in cold regions in China-A life-cycle assessment approach. Sustainability 2016, 8, 1047. [CrossRef]

10. Suzuki, M.; Oka, T.; Okada, K. The estimation of energy consumption and $\mathrm{CO} 2$ emission due to housing construction in Japan. Energy Build. 1995, 22, 165-169. [CrossRef]

11. CLT Handbook: Cross Laminated Timber; FP Innovation Special Publication SP-529E; U.S. Edition: St. Jean Pointe-Claire, QC, Canada, 2013.

12. EN 1995-1-1: 2004. Eurocode 5: Design of Timber Structures-Part-1-1: General Rules and Rules for Buildings; European Committee for Standardization (CEN): Brussels, Belgium, 2003.

13. EN 1998-1: 2004. Eurocode 8: Design of Structures for Earthquake Resistance, Part 1: General Rules, Seismic Actions and Rules for Buildings; CEN: Brussels, Belgium, 2003.

14. Kleinhenz, M.; Winter, S.; Dietsch, P. Eurocode 5-A halftime summary of the revision process. In Proceedings of the WCTE, Vienna, Austria, 22-25 August 2016.

15. Follesa, M.; Fragiacomo, M.; Casagrande, D.; Tomasi, R.; Piazza, M.; Vassallo, D.; Canetti, D.; Rossi, S. The New Provisions for the Seismic Design of Timber Buildings in Europe. Eng. Struct. 2018, 168, 736-747. [CrossRef]

16. Ceccotti, A. New technologies for construction of medium-rise buildings in seismic regions: The XLAM case. Struct. Eng. Int. 2008, 18, 156-165. [CrossRef]

17. Ceccotti, A.; Sandhaas, C.; Okabe, M.; Yasumura, M.; Minowa, C.; Kawai, N. SOFIE project-3D shaking table test on a seven-storey full-scale cross-laminated timber building. Earth Eng. Struct. Dyn. 2013, 42, 2003-2021. [CrossRef]

18. Van de Lindt, J.W.; Furley, J.; Amini, M.O.; Pei, S.; Tamagnone, G.; Barbosa, A.R.; Rammer, D.; Line, P.; Fragiacomo, M.; Popovski, M. Experimental seismic behaviour of a two-story CLT platform building. Eng. Struct. 2019, 183, 408-422. [CrossRef]

19. Dong, W.; Li, M.; Ottenhaus, L.; Lim, H. Ductility and overstrength of nailed CLT hold-down connections. Eng. Struct. 2020, 215, 110667. [CrossRef]

20. Fragiacomo, M.; Dujic, B.; Sustersic, I. Elastic and ductile design of multi-storey crosslam massive wooden buildings under seismic actions. Eng. Struct. 2011, 33, 3043-3053. [CrossRef]

21. Gavric, I.; Fragiacomo, M.; Ceccotti, A. Cyclic behavior of typical metal connectors for cross-laminated (CLT) structures. Mater. Struct. 2015, 48, 1841-1857. [CrossRef]

22. Pozza, L.; Saetta, A.; Savoia, M.; Talledo, D. Angle bracket connections for CLT structures: Experimental characterization and numerical modeling, Construct. Build. Mater. 2018, 191, 95-113. [CrossRef]

23. Izzi, M.; Casagrande, D.; Bezzi, S.; Pasca, D.; Follesa, M.; Tomasi, R. Seismic behavior of Cross-Laminated Timber structures: A state-of-the-art review. Eng. Struct. 2018, 170, 45-52. [CrossRef] 
24. Trutalli, D.; Marchi, L.; Scotta, R.; Pozza, L. Capacity design of traditional and innovative ductile connections for earthquakeresistant CLT structures. Bull. Earth Eng. 2019, 17, 2115-2136. [CrossRef]

25. Latour, M.; Rizzano, G. Cyclic behavior and modeling of a dissipative connector for Cross-Laminated Timber panel buildings. J. Earth Eng. 2015, 19, 137-171. [CrossRef]

26. Scotta, R.; Marchi, L.; Trutalli, D.; Pozza, L. A dissipative connector for CLT buildings: Concept, design and testing. Materials 2016, 9, 139. [CrossRef] [PubMed]

27. UNI EN 14081-1:2016. Timber Structures-Strength Graded Structural Timber with Rectangular Cross Section-Part 1: General Requirements; CEN: Brussels, Belgium, 2001.

28. ETA-14/0349. European Technical Assessment, Issued in Accordance with Regulation EU $N^{\circ}$ 305/2011, 2019; European Commission: Brussels, Belgium, 2019.

29. DIN EN 1995-1-1/NA. National Annex-Nationally Determined Parameters-Eurocode 5: Design of Timber Structures-Part 1-1: GeneralCommon Rules and Rules for Buildings; Deutsche Institute fur Normung (DIN): Berlin, Germany, 2013.

30. ÖNORM B 1995-1-1. Eurocode 5: Design of Timber Structures-Part 1-1: General Common Rules and Rules for Buildings-National Specification for the Implementation of ONORM EN 1995-1-1, National Comments and National Supplements; Austrian Standards Institute (ASI): Vienna, Austria, 2015.

31. Italian Technical Document CNR DT 2016/2018-R1. Instruction for Design, Execution and Control and Timber Construction; National Council of Research: Rome, Italy, 2018.

32. International Building Code (IBC). Produced by International Code Council; International Building Code (IBC): Washington, DC, USA, 2015.

33. American Wood Council. National Design Specification (NDS) for Wood Construction; American Wood Council: Leesburg, VI, USA, 2015.

34. Japan CLT Association. Manual of CLT Construction Design for Practitioners; Edition Detail: Osaka, Japan, 2018.

35. Australian Cross Laminated Timber Panel Structural Guide. In Australian Design Guide; Australian Edition: New South Wales, Australia, 2017.

36. Wallner-Novak, M.; Koppelhuber, J.; Pock, K. Cross-Laminated Timber Structural Design-Basic Design and Engineering Principles According to Eurocode; proHolz Austria: Vienna, Austria, 2013.

37. Shahnewaz, M.; Popovski, M.; Tannert, T. Deflection of cross-laminated timber shear walls for platform-type. Eng. Struct. 2020, 221, 111091. [CrossRef]

38. Chen, Z.; Popovski, M. Mechanics-based analytical models for balloon-type cross-laminated timber (CLT) shear walls under lateral loads. Eng. Struct. 2020, 208, 109916. [CrossRef]

39. Johansen, K.W. Theory of timber connections. Int. Ass Bridge Struct. Eng. 1949, 9, 249-262.

40. Flatscher, G.; Bratulic, K.; Schickhofer, G. Experimental tests on cross-laminated timber joints and walls. Proc. ICE Struct. Build. 2015, 168, 868-877. [CrossRef]

41. Popovski, M.; Schneider, J.; Schweinsteiger, M. Lateral load resistance of cross-laminated wood panels. In Proceedings of the WCTE, Riva del Garda, Italy, 20-24 June 2010.

42. Tomasi, R.; Smith, I. experimental characterization of monotonic and cyclic loading responses of CLT panel-to-foundation angle-brackets connections. J. Mater. Civ. Eng. 2015, 27, 04014189. [CrossRef]

43. Latour, M.; Rizzano, G. Seismic behavior of cross-laminated timber equipped with traditional and innovative connectors. Arch. Civ. Mech. Eng. 2017, 17, 382-399. [CrossRef]

44. Pozza, L.; Ferracuti, B.; Massari, M.; Savoia, M. Axial-shear interaction on CLT hold-down connections-Experimental investigation. Eng. Struct. 2018, 160, 95-110. [CrossRef]

45. Liu, J.; Lam, F. Experimental test of Cross-Laminated Timber connections under bidirectional loading. In Proceedings of the WCTE, Vienna, Austria, 22-25 August 2016.

46. Franco, L.; Pozza, L.; Saetta, A.; Savoia, M.; Talledo, D. Strategies for structural modeling of CLT panels under cyclic loading conditions. Eng. Struct. 2019, 198, 109476. [CrossRef]

47. Gavric, I.; Fragicomo, M.; Ceccotti, A. Cyclic behavior of CLT wall systems: Experimental tests and analytical prediction models. J. Struct. Eng. 2015, 141, 04015034. [CrossRef]

48. Blass, J.H.; Fellmoser, P. Design of solid wood panels with cross layers. In Proceedings of the WCTE 2004, Lahti, Finland, 14-17 June 2004; pp. 543-548.

49. Sandoli, A.; Moroder, D.; Pampanin, S.; Calderoni, B. Simplified analytical models for coupled CLT walls. In Proceedings of the WCTE, Vienna, Austria, 22-25 August 2016.

50. Sandoli, A.; D'Ambra, C.; Ceraldi, C.; Calderoni, B.; Prota, A. Role of perpendicular to grain compression properties on the seismic behavior of CLT walls. J. Build. Eng. 2021, 34, 101889. [CrossRef]

51. Blass, H.J.; Fellmoser, P. Influence of rolling shear modulus on strength and stiness of structural bonded timber elements. In Proceedings of the CIB-W18 Meeting, Edinburg, TX, USA, August 2004.

52. Sandoli, A.; Calderoni, B. The rolling shear influence on the out-of-plane behavior of CLT panels: A comparative analysis. Buildings 2020, 10, 42. [CrossRef]

53. Corpataux, L.; Okuda, S.; Kua, W.H. Panel and plate properties of Cross-laminated timber (CLT) with tropical fast-growing timber species in compliance with Eurocode 5. Constr. Build. Mater. 2020, 261, 119672. [CrossRef] 
54. Lim, H.; Tripathi, S.; Li, M. Rolling shear modulus and strength of cross-laminated timber treated in micronized copper azole type C (MCA-C). Constr. Build. Mater. 2020, 259, 120419. [CrossRef]

55. Minghao, L. Evaluating rolling shear strength properties of cross-laminated timber by short-span bending tests and modified planar shear tests. J. Wood Sci. 2017, 63, 331-337.

56. Zhou, Q.; Gong, M.; Chui, Y.H.; Mohammad, M. Measurement of rolling shear modulus and strength of cross laminated timber fabricated with black spruce. Constr. Build. Mater. 2017, 64, 379-386. [CrossRef]

57. Saavedra Flores, E.J.; Saavedra, K.; Hinojosa, H.; Chandra, Y.; Das, R. Multi-scale modeling of rolling shear failure in crosslaminated timber structures by homogenization and cohesive zone models. Int. J. Solid Struct. 2016, 81, 219-232. [CrossRef]

58. Sturzenbecher, R.; Hofstetter, K.; Eberhardsteiner, J. Structural design of Cross Laminated Timber (CLT) by advanced plate theories. Comp. Sci. Technol. 2010, 70, 1368-1379. [CrossRef]

59. Kreuzinger, H. Mechanically jointed beams and columns. Timber Eng. 1995, 1, B11.

60. Casagrande, D.; Rossi, S.; Sartori, T.; Tomasi, R. Proposal of an analytical procedure and a simplified numerical model for elastic response of single-storey timber shearwalls. J. Constr. Build. Mater. 2016, 102, 1101-1112. [CrossRef]

61. Gavric, I.; Popovski, M. Design models for CLT shear walls and assemblies based on connection properties. Int. Netw. Timber Eng. Res. 2014, 15, 267-280.

62. Pei, S.; Lindt, J.V.D.; Popovski, M. Approximate R-factor for cross-laminated timber walls in multi-story buildings. J. Arch. Eng. 2012, 19, 245-255. [CrossRef]

63. Tomasi, R. CLT Course at FPS COST Action FP1004-Enhance Mechanical Properties of Timber, Engineered Wood Products and Timber Structures; CLT Training School, University of Trento: Trento, Italy, 2014.

64. Tamagnone, G.; Rinaldin, G.; Fragiacomo, M. A novel method for non-linear design of CLT wall systems. Eng. Struct. 2018, 167, 760-771. [CrossRef]

65. Franco, L.; Pozza, L.; Saetta, A.; Talledo, D. Enhanced N-V interaction domains for the design of CLT shear wall based on coupled interaction models. Eng. Struct. 2021, 231, 111607. [CrossRef]

66. Pozza, L.; Trutalli, D. An analytical formulation of the q-factor for mid-rise CLT buildings based on parametric numerical analyses. Bull. Earth Eng. 2015, 13, 3449-3469. [CrossRef]

67. Tran, K.D.; Jeong, Y.G. Effects of wood species, connection system, and wall-support interface type on cyclic behaviours of cross-laminated timber (CLT) walls under lateral loads. Constr. Build. Mater. 2021, 280, 122450. [CrossRef]

68. Yasumura, M.; Kobayashi, K.; Okabe, M.; Miyake, T.; Matsumoto, K. Full-scale tests and numerical analysis of low-rise CLT structures under lateral loading. J. Struct. Eng. 2016, 142, E4015007. [CrossRef]

69. Izzi, M.; Polastri, A.; Fragiacomo, M. Investigating the hysteretic behavior of Cross- Laminated Timber wall systems due to connections. J. Struct. Eng. 2018, 144, 04018035. [CrossRef]

70. Mestar, M.; Doudak, G.; Polastri, A.; Casagrande, D. investigating the kinematic modes of CLT shear-walls with openings. Eng. Struct. 2021, 228, 111475. [CrossRef]

71. Moroder, D.; Sarti, F.; Pampanin, S.; Smith, T.; Buchanan, A.H. Higher mode effects in multi-storey timber buildings with varying diaphgrams flexibility. In Proceedings of the NZSEE Conferernce, Christchurch, New Zealand, 1-3 April 2016.

72. Moroder, D.; Smith, T.; Armstrong, J.; Young, B.; Buchanan, A.H. Challenges and solutions in the design of a 10 storey CLT building. N. Zealand Timber Design 2017, 25, 4 .

73. Flaig, M.; Blass, H.J. Shear strength and shear stiffness of CLT-beams loaded in plane. In Proceedings of the CIB-W18 Meeting 46, Vancouver, BC, Canada, 26-29 August 2013. paper 46-12-3.

74. Applied Technology Council. ATC-7 Guidelines for the Design of Horizontal Wood Diaphgrams; Applied Technology Council: Berkeley, CA, USA, 1981.

75. Vassallo, D.; Follesa, M.; Fragiacomo, M. Seismic design of a six-storey CLT building in Italy. Eng. Struct. 2018, 175, 322-338. [CrossRef]

76. Christovasilis, I.P.; Riparbelli, L.; Rinaldin, G.; Tamagnone, G. Methods for practice-oriented linear analysis in seismic design of Cross Laminated Timber buildings, Soil Dynam. Earthq. Eng. 2020, 128, 105869.

77. Rinaldin, G.; Amadio, A.; Fragiacomo, M. A component approach for the hysteretic behavior of connections in cross-laminated wooden structures. Earth Eng. Struct. Dyn. 2013, 42, 2023-2042. [CrossRef]

78. Masroor, M.; Doudak, G.; Casagrande, D. The effect of bi-axial behavior of mechanical anchors on the lateral response of multi-panel CLT sharwalls. Eng. Struct. 2020, 224, 111202. [CrossRef]

79. Schneider, J.; Karacabeyli, E.; Popovski, M.; Steimer, S.F.; Tesfamariam, S. Damage assessment of connections used in CrossLaminated Timber subjected to cyclic loads. J. Perform Facil. 2014, 28, A4014008.

80. Piestley, N.J.M.; Tao, R.J. Seismic Response of Precast Prestressed Concrete Frames with Partially Debonded Tendons. PCI J. 1993, 38, 58-69. [CrossRef]

81. Palermo, A.; Pampanin, S.; Buchanan, A.; Newcombe, M. Seismic design of multi-storey buildings using laminated veneer lumber (LVL). In Proceedings of the New Zealand Earthquake Engineering conference NZEES, Christchurch, New Zealand, 11-13 March 2005.

82. Sarti, F.; Palermo, A.; Pampanin, S. Quasi static cyclic testing of two-thirds scale un-bonded posttensioned rocking dissipative timber walls. J. Struct. Eng. 2016, 142, E40115005. 